\title{
The impact of permeability heterogeneity on water-alternating-gas displacement in highly stratified heterogeneous reservoirs
}

\author{
Mohammad Yunus Khan $^{1}$ (D) Ajay Mandal ${ }^{2}$
}

Received: 28 August 2021 / Accepted: 20 October 2021 / Published online: 30 October 2021

(c) The Author(s) 2021

\begin{abstract}
Availability of gases at the field level makes attractive to water-alternating-gas (WAG) process for low viscosity and light oils carbonate reservoir. However, impact of reservoir heterogeneity on WAG performance is crucial before field application. In general, ramp carbonates have heterogeneity due to variation of permeability and porosity. However, WAG performance significantly affected by permeability variations. This article investigates merits and demerits of WAG displacement due to permeability heterogeneities such as permeability anisotropy, high permeability streaks (HKS), matrix permeability, dolomite and thin dense stylolite layers. High-resolution compositional simulations with tuned equation of state (EoS) were carried out using 2D and 3D sector models. The study focuses on WAG performance in terms of oil recovery, vertical sweep, solvent utilization, gas oil ratio (GOR), water cut (WCT), WAG response time, gravity override, hysteresis, un-contacted oil saturation and economics. The results of simulation show that the heterogeneous reservoir provides initially faster WAG response, lower expected ultimate recovery (EUR), faster gas breakthrough, higher GOR and WCT production compared to homogeneous reservoir. The gas gravity override at smaller wells spacing is less in homogeneous reservoir as compared to heterogeneous reservoir, but it is reverse in case of larger well spacing. In heterogeneous reservoir, the HKS shows significant gas override resulting in poor vertical sweep due to capillary holding, and the high permeability dolomite layer shows early water breakthrough. This reservoir has higher solvent utilization in initial stage, and then, it becomes nearly equal to homogeneous reservoir. Simulation in both reservoirs overestimates incremental recovery of 2-3\% OOIP at one pore volume injection because of not involving un-contacted oil saturation as predicted in core flood. The findings of this study will help to understand WAG performance and design in highly heterogeneous reservoirs for field applications.
\end{abstract}

Ajay Mandal

mykhan@kockw.com

Kuwait Oil Company-KOC, Ahmadi, Kuwait

2 Indian Institute of Technology (ISM), Dhanbad, India 


\section{Graphical abstract}
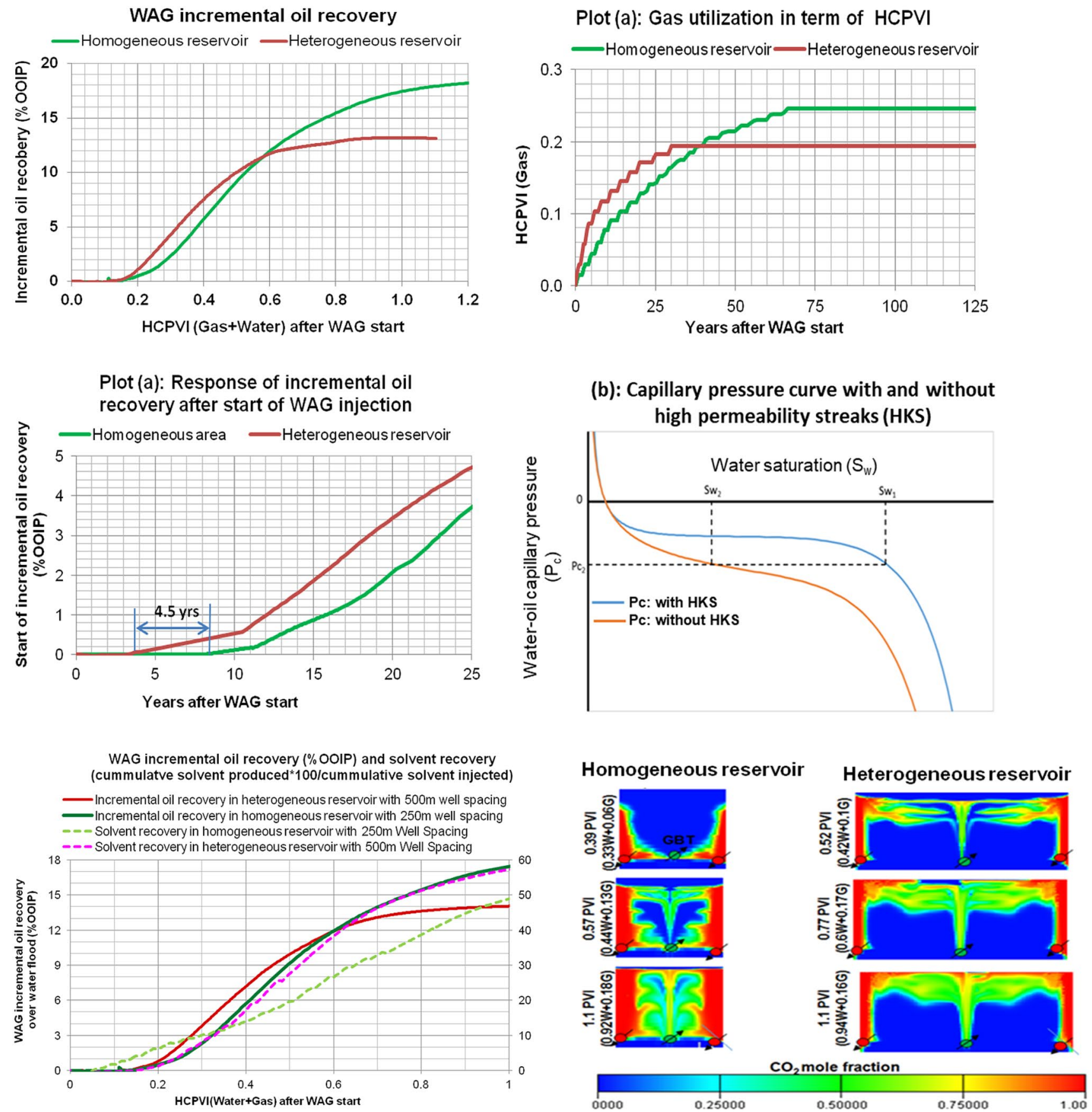

Keywords WAG permeability heterogeneities - Oil recovery · Gas utilization - Gravity override $\cdot$ Economics $\cdot$ Hysteresis · Un-contacted oil saturation and numerical simulation

$\begin{array}{llll}\text { Abbreviations } & & \text { OOIP } & \text { Original oil-in-place } \\ \text { EOR } & \text { Enhanced oil recovery } & \text { HCPVI } & \text { Hydrocarbon pore volume injection } \\ \text { WAG } & \text { Water-alternating-gas } & \text { GOR } & \text { Gas oil ratio } \\ \text { TWAG } & \text { Tapered water-alternating-gas, } & \text { WCT } & \text { Water cut } \\ & \text { respectively } & \text { GBT } & \text { Gas breakthrough }\end{array}$




\begin{tabular}{|c|c|}
\hline WBT & Water breakthrough, respectively \\
\hline HKS & High permeability streaks \\
\hline EoS & Equation of state \\
\hline MMP & Minimum miscible pressure, respectively \\
\hline IFT & Interfacial tension \\
\hline SUF & Solvent utilization factor \\
\hline G & Gravity viscous number, respectively \\
\hline $\mathrm{RF}$ & Recovery factor (\%OOIP) \\
\hline EUR & Expected ultimate recovery (\%OOIP) \\
\hline $\mathrm{P}_{\mathrm{c}}$ & Capillary pressure \\
\hline $\mathrm{K}_{\mathrm{rw}}$ & Water relative permeability \\
\hline $\mathrm{K}_{\mathrm{rg}}$ & Gas relative permeability \\
\hline $\mathrm{K}_{\mathrm{v}} / \mathrm{K}_{\mathrm{h}}$ & $\begin{array}{l}\text { Vertical to horizontal permeability ratio, } \\
\text { respectively }\end{array}$ \\
\hline $\mathrm{D}$ & $\begin{array}{l}\text { Represent to sector model dimension, } \\
\text { i.e., } 2 \mathrm{D} \text { or } 3 \mathrm{D}\end{array}$ \\
\hline$\eta_{\mathrm{vol}}$ & Volumetric sweep efficiency \\
\hline$\eta_{d}$ & Displacement sweep efficiency \\
\hline$\eta_{t}$ & Total sweep efficiency, respectively \\
\hline $\mathrm{S}_{\mathrm{w}}$ & Water saturation \\
\hline $\mathrm{S}_{\text {orm }}$ & Un-contacted oil saturation \\
\hline M1 to M6 & $\begin{array}{l}\text { Major porous layers of the subject } \\
\text { reservoir }\end{array}$ \\
\hline D1 to D6 & $\begin{array}{l}\text { Thin stylolite (dense) intervals in the } \\
\text { subject reservoir }\end{array}$ \\
\hline MDT and RFT & $\begin{array}{l}\text { Modular dynamic tester and repeat for- } \\
\text { mation tester }\end{array}$ \\
\hline$\Delta \rho$ & $\begin{array}{l}\text { Density difference (displaced to displac- } \\
\text { ing fluids) }\end{array}$ \\
\hline $\mathrm{V}$ & Injected fluid velocity \\
\hline $\mathrm{K}_{\mathrm{v}}$ & Vertical permeability \\
\hline $\mathrm{k}_{\mathrm{h}}$ & Horizontal permeability \\
\hline $\mathrm{L}$ & Length \\
\hline $\mathrm{H}$ & Height \\
\hline M & Mobility ratio \\
\hline $\mathrm{g}$ and $\mu_{\mathrm{o}}$ & $\begin{array}{l}\text { Gravitational constant and oil viscosity, } \\
\text { respectively }\end{array}$ \\
\hline $\mathrm{C}_{\mathrm{in}}$, & Net cash inflow (revenue) during period $t$ \\
\hline $\mathrm{C}_{\text {out }}$ & Net cash investment during period $t$ \\
\hline $\mathrm{C}_{\mathrm{o}}$ & Investment costs \\
\hline $\mathrm{r}$ and $\mathrm{t}$ & $\begin{array}{l}\text { Discount rate and number of years, } \\
\text { respectively }\end{array}$ \\
\hline CAPEX & Capital expenditure cost $(\$)$ \\
\hline UDC & Unit development cost $(\$ / \mathrm{bbl})$ \\
\hline UTC & Unit technical cost $(\$ / \mathrm{bbl})$ \\
\hline NPV & Net present value (\$), respectively \\
\hline
\end{tabular}

\section{Introduction}

After uneconomic primary and secondary production from limited recoverable resources, the IOR (improved oil recovery) and EOR (enhanced oil recovery) methods evolve to meet the growing global hydrocarbon demand (Dong et al., 2005). While gas-based EOR methods can be more attractive for low viscosity and light oil reservoir if gases are available at reservoir level. Theoretically, if favorable mobility is achieved, the residual oil saturation may approach zero in the swept area of the reservoir with miscible gas injection as capillary number becomes infinite (Shahverdi et al. 2011). Therefore, miscible gas-based EOR process is considered as most suitable method of currently available EOR technologies (Chen et al. 2010). The dominating mechanisms of miscible gas flooding to improve oil recovery are lowering interfacial, reducing oil viscosity and increasing capillary number (He et al. 2018; Li et al. 2016, 2020; Lv et al. 2017).

The $\mathrm{CO}_{2}$ gas is the most commonly used gas during miscible injection in the temperatures range of 40 to $100{ }^{\circ} \mathrm{C}$, oil viscosity range of $0.25-1.5 \mathrm{cp}$ and API gravity range of $35.1-45^{\circ}$ (Ahdaya and Imqam, 2020). However, the injected gases result in poor sweep efficiency caused by viscous fingering, bypass oil and early breakthrough due to reservoir heterogeneities such as high permeability streaks (HKS), high permeability dolomite layers, fault and fractures (Birarda, 1990). Hence, gas injection results in poor macroscopic sweep. But the advantages of microscopic (displacement) sweep by gas overcome the disadvantages of macroscopic (volumetric) sweep (Hustad and Holt, 1992; Touray, 20,013). While the gas-assisted gravity drainage (GAGD) processes can provide higher oil recovery compared to continuous gas injection (CGI) and water-alternating-gas injection (WAG) processes, the GAGD process has advantage of natural segregation of reservoir fluids to provide gravity-stable oil displacement by injecting gas through vertical wells to formulate a gas cap which allows oil and water drainage down to the horizontal producers (Mahmoud and Rao, 2007; Al-Mudhafar et al. 2017a; 2017b). Mahmoud and Rao (2007) showed that various mechanisms are responsible for high oil recoveries in GAGD process, i.e., Darcy-type displacement until gas breakthrough, gravity drainage after breakthrough and film drainage in the gas invaded regions. They also demonstrated that GAGD is also applicable in naturally fractured reservoirs. However, the GAGD method is not suitable for this field as the thickness of pay zone is low for vertical sweep efficiency and causes early breakthrough of injected gas (Tavousi et al. 2016). In addition, CGI leads to lower recovery compared to the WAG process, due to its unfavorable mobility ratio, while the main goal of the WAG projects is to control the mobility and to decrease the problem of viscous fingering, leading to improved oil recovery by combining the benefits of gas injection (GI) and water flooding (WF) (Afzali et al. 2018). Therefore, wateralternating-gas (WAG) injection was developed in industry to overcome these problems (Knappskog, 2012; Pariani and McColloch, 1992; Kulkarni and Rao, 2005; Zahoor et al.

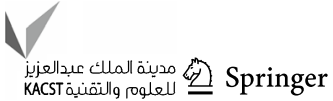


2011; Tabatabaei Nezhad et al. 2006), which can increase displacement sweep efficiency by creating favorable mobility ratio (Christensen et al. 2001).

Actually, the displacement sweep efficiency provides oil mobilization at the pore spaces level after sweeping by the injected fluid (Ahmed, 2018), which depends on oil composition, slug size, reservoir pressure, rock wettability, mobility ratio, temperature, rock-pore geometry/structure, saturation history of rock-fluid system, fluid behavior and fluid properties (Ghedan, 2009), while the total oil recovery $\left(\eta_{t}\right)$ of gas or WAG displacement is the product of displacement sweep efficiency $\left(\eta_{\mathrm{d}}\right)$ and volumetric sweep efficiency $\left(\eta_{\mathrm{vol}}\right)$ (Thakur and Satter, 1998) as below:

$\eta_{\mathrm{t}}=\eta_{\mathrm{d}} * \eta_{\mathrm{vol}}$, where $\eta_{\mathrm{vol}}=\eta_{\mathrm{A}} * \eta_{\mathrm{v}}$

where $\eta_{\mathrm{A}}$ and $\eta_{\mathrm{v}}$ are the areal and vertical sweep efficiencies, respectively.

The volumetric sweep efficiency is the product of vertical and areal sweep efficiencies (Ahmed, 2018). The vertical sweep efficiency is the percentage of cumulative height of pay zone vertical section of that contacted by injected fluid, and the areal sweep efficiency is expressed as the fraction of pattern area from which reservoir fluid is displaced by the injected fluid. The vertical sweep efficiency depends on mobility ratio, hydrocarbon pore volume injection (HCPVI), flow rate, density difference of displacing to displaced fluids, vertical permeability, high permeability streaks, baffles, stylolite layers and dolomite layers (Ghedan 2009), while areal sweep efficiency is affected by reservoir fracture, fault, directional permeability, mobility ratio, injection pattern, formation dip angle and dip azimuth. The local displacement efficiency is greatly affected by injected solvent miscibility with the in situ oil (Stalkup 1983; Henderson et al. 1998). The hysteresis impact on WAG displacement is important due to strong flow reversals (Spiteri and Juanes 2004).

Therefore, the performance of WAG displacements in terms of microscopic and macroscopic level, the oil production is highly affected by some critical parameters, categorized based on their controllability, i.e., uncontrollable and controllable parameters (Leach and Yellig 1981; Green and Willhite 1998; Heinrich et al. 2003; Clancy et al. 1985), as shown in Fig. 1. The controllable parameters can be changed/possibly optimized to increase the profitability of WAG displacement, while uncontrollable parameters such as reservoir heterogeneities, stratification and petro-physical properties are either impossible or too difficult or costly to modify (Birarda 1990).

However, the permeability heterogeneities and stratification are the main concern, which typically affect the flow characteristic and so the oil recovery, especially when reservoir is produced through gas injection, which affect stability of flood front (Figuera et al. 2014; Cuesta and Merrit, 1982). In general, ramp carbonates have heterogeneity due to variation of permeability and porosity. However, WAG performance is significantly affected by permeability variations (Pande 1992, Araktingi and Orr, 1990, Perrin and Benson 2010, Zhao et al. 2011, Zhang et al. 2013, Lv et al. 2017, Al-Bayati et al. 2019). The permeability is influenced by the rock grain size, shape, size distribution as well as the grain arrangement and the extent of compaction. The permeability heterogeneities

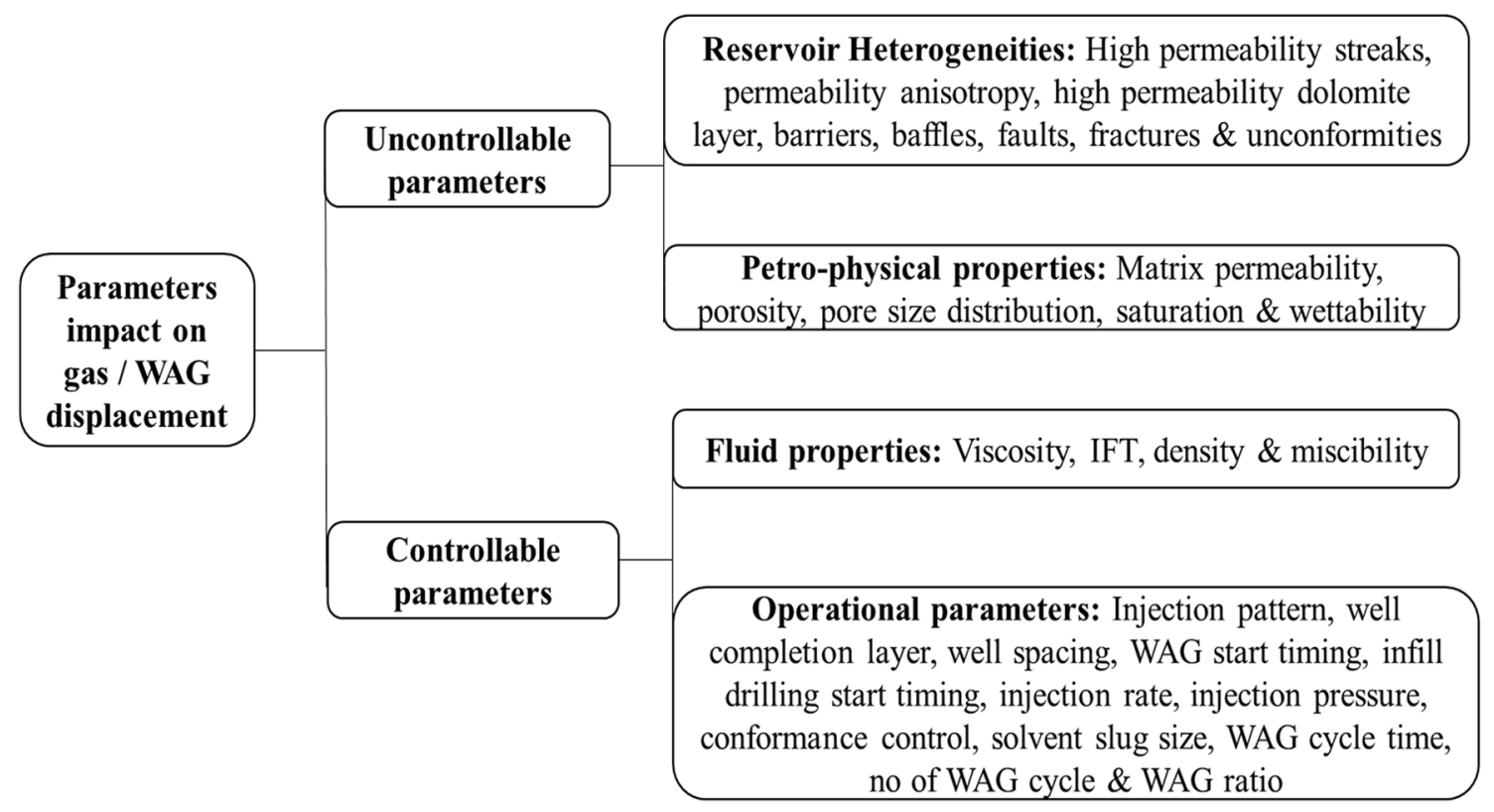

Fig. 1 Uncontrollable and controllable parameters in gas and WAG displacements

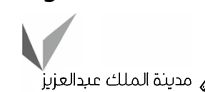


are mainly present due to non-uniform pore size distribution, which varies with the degrees of interconnectivity in majority of the reservoirs and affects the stability of flood front. These heterogeneities can be characterized based on fluid movement communication between the layers of the reservoir (Muskat 1981). The effective flow communication of layers causes difficulties in presence of lenses, high permeability streaks (HKS), unconformities, faults, fractures, high permeability dolomite layer, thin stylolite layers, barriers, baffles, vertical permeability anisotropy and lateral facies variation. The permeability heterogeneities cause different impacts on WAG performance as mentioned below:

- The under-riding and overriding phenomena will leave a large amount of oil due to un-swept (Chang-lin et al. 2013);

- Gravity segregation accrues due to water flow bottom and gas flowup (Panda et al. 2009);

- The permeability anisotropy and stratification affect vertical conformance (Surguchev, 1992);

- High stratifications of the reservoir lead to bypassing considerable residual oil in the layers with less permeability as displacement front tends to move along the highly permeable layers (Donaldson et al. 1989);

- A higher vertical permeability results in perpendicular crossflow to the bulk flow (Rogers and Grigg, 2000);

- The increase in vertical transmissibility results decreases in oil recovery (Bunge and Radke, 1982);

- Significant impact of $\mathrm{K}_{\mathrm{v}} / \mathrm{K}_{\mathrm{h}}$ on the overall production efficiency (Egermann, 2000);

- The low permeable layers decrease fluid flow velocity in the reservoir and result in gravity segregation problems (Kulkarni, 2003);

- The crossflow created by capillary imbibitions assists the vertical sweep efficiency for favorable mobility ratio in immiscible displacement in heterogeneous reservoir

Fig. 2 Reservoir permeability heterogeneity impact on different parameters in WAG displacement
(CRAIG, 1971; Yokoyama and Lake, 1981; Hawes, 1986);

- Flow into each layer is essentiality proportional to the fraction of the overall system $\mathrm{KH}$ and almost independent of WAG ratio (Knappskog, 2012);

- The relative permeability of each phase might not be accurately applicable in WAG due to the cyclic hysteresis nature (DiCarlo, 2000; Fenwick and Blunt, 2013);

- IFT affects the relative permeability curvatures (Harbert, 1983; Henderson et al. 1998; Chen et al. 1999; Touray, 2013);

- Early gas breakthrough is caused not only by mobility ratio but also by the reservoir heterogeneity and especially high permeable layers (Caudle and Dyes, 1958; Gorell, 1990a, b; Lien et al. 1998; Chakravarthy et al. 2006).

Therefore, reservoir permeability heterogeneity impacted on several parameters, which affect WAG performance as shown in Fig.2.

Therefore, it is important to understand the positive and negative effect of permeability heterogeneities on WAG displacement performance before WAG field application. Some of the recent studies carried out for permeability heterogeneity impact on WAG performance are presented in literature as specified below:

Jones et al. (1989) presented that the oil recovery is a strong function viscosity ratio of fluids and thief zone to matrix permeability ratio. Gorell et al. (1990) reported that vertical WAG displacement is highly affected by the flow communications between the different types of permeability zones in the reservoir. Gharbi et al. (1997) investigated the effect of heterogeneity on the performance of EOR processes with horizontal wells three-dimensional, finite difference, chemical flood simulator (UTCHEM). They concluded that the performance of EOR processes with horizontal wells is strongly affected by the permeability variation and the spatial correlation of the reservoir heterogeneity. The
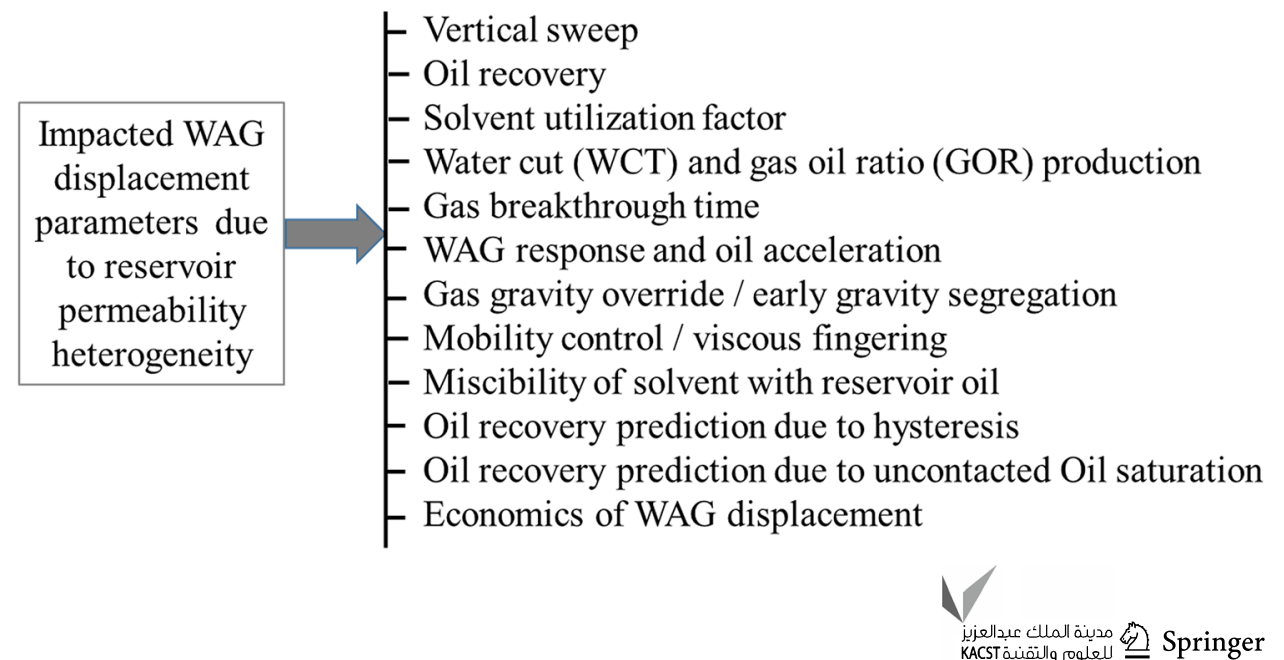
combination of high permeability variation and high correlation length significantly reduces the performance of horizontal wells. Christensen et al. (2000) reported the oil recovery differences with and without hysteresis cases in WAG displacement using in 2-D and 3-D compositional numerical simulations. Rogers and Grigg (2000) showed that larger portion of solvent slug passes through HKS, which losses the injectivity in low permeability layers due to less solvent movement in low permeability layers. White et al. (2001) carried out experiments to examine the variability in production predictions caused by geological heterogeneity and uncertainty with new method. Their approach can be used for model comparison, sensitivity analysis and estimation of probability distributions of geological model parameters. Johns and Dindoruk (2013) analyzed the influence of solvent enrichment impact on oil recovery with different reservoir heterogeneity and WAG parameters. They indicated that continuous slug injection outperforms WAG with richer gases in low $\mathrm{K}_{\mathrm{v}} / \mathrm{K}_{\mathrm{h}}$ heterogeneous reservoir. Singhal and Springer (2006) have characterized the reservoir heterogeneity based on performance of infill wells in waterfloods. They divided reservoir into horizontal or vertical "compartments" due to spatial variations in reservoir attributes (such as permeability, thickness, environment of deposition and post-depositional changes). Schembre and Kovscek (2003) showed that the capillary forces dominate in the area of bypassed oil in fine-scale heterogeneity porous media during WAG displacement because non-wetting phase not overcomes capillary force. Ghomian et al. (2008) investigated the impact of hysteresis in relative permeability on $\mathrm{CO}_{2}$ WAG displacement and $\mathrm{CO} 2$ sequestration using compositional simulator-based correlations, WAG ratio, solvent slug size and reservoir heterogeneity. Rashid et al. (2012) introduced an improved heterogeneity/homogeneity index to characterize heterogeneity and rank geological realizations in terms of their impact on secondary-recovery performance. They showed that index's ranking ability is preserved for miscible and immiscible displacements at different viscosity/mobility ratios. Jeong et al. (2014) studied reservoir heterogeneity and WAG ratio impact on incremental oil through NPV. They showed that the optimum WAG ratio is altered with reservoir heterogeneities. Nguyen et al. (2015) provided more realistic and unbiased evaluation of reservoir heterogeneity and their impact on improved oil recovery. They used new approach involving the integration of geological software, a reservoir simulator and a robust optimizer in a closed loop for generating multiple geologically driven realizations and uncertainty assessment of different recovery processes. They concluded simulation results that the lithofacies has a dominant effect on oil recovery in all recovery processes. The coarsening-upward distribution demonstrates superior performances over the fining-upward distribution. Additionally, the heterogeneity of lithofacies also affects the flow direction and injectivity of displacing fluids and, consequently, influences the ultimate oil recovery factor. Saneifar et al. (2017) demonstrated that WAG injectivity loss is approximately $30 \%$ higher in heterogeneous reservoir compared to homogeneous reservoir. Yu et al. (2017) showed that displacement sweep depends on different flow unit, which mainly affected by permeability in low permeability reservoir. Debbabi et al. (2017) identified that vertical sweep significantly affected by mobility contrast in WAG of stratified reservoir. Pan et al. (2018) developed a practical method to determine permeability anisotropy using inter-well transient tests at different azimuths in heterogeneous reservoirs. Hoare and Coll (2018) carried out simulation and found that hysteresis effects were shown by simulation to improve the recovery factor from WAG injection compared to water injection by another 10\% (making 15\% total improvement), while WAG cycle length has a relatively minor impact on recovery factor. Khorsandi and Johns (2018) reported that reservoir dip angle, permeability and reservoir heterogeneity, wettability, pore structure, fluid composition and water and gas connectivity are having a significant impact on oil recovery. Al-Mudhafar et al. (2018) studied the effects of reservoir heterogeneity and anisotropy on cyclic $\mathrm{CO} 2$-assisted gravity drainage (GAGD) process performance in a heterogeneous multi-layering sandstone reservoir. They concluded that the impact of permeability anisotropy on the GAGD process is higher than that of heterogeneity, because the main concept of GAGD process considers vertical fluid movements from the top-layer injection wells to the horizontal producers. Al-Bayati et al. (2019) demonstrated that crossflow in the different permeability layers has negative influence on WAG displacement incremental oil recovery due to reduction mobilized oil by crossflow in the presence of HKS. Ren et al. (2019) identified that optimal WAG ratio (at the minimal net utilization factor) increases with decrease in permeability anisotropy. This net solvent utilization factor depends on reservoir heterogeneities, well injection pattern and WAG operating ratio. Xie et al. (2020) observed lower ultimate oil recovery with increase of permeability ratio between zones.

As per our knowledge, most of the studies regarding permeability heterogeneity impact on WAG displacement not in integrated form as discussed in above paragraph. We have investigated in depth all permeability heterogeneities impact on WAG displacement as integrated form and carried out economic study to understand combined effect of all permeability heterogeneities in both heterogeneous and homogeneous reservoirs. Therefore, the novelty of this article is merits and demerits investigations of permeability heterogeneities of ramp carbonates on WAG displacement performance. First, the fine-gridded 3D sector of synthetic as well as real field models of homogeneous and heterogeneous reservoirs was constructed to carry out compositional EOR simulation for WAG displacement using tuned 
9-components equation of estate (EoS). The sector model's pressure was maintained slightly above initial reservoir pressure (4200psi), which was above MMP to achieve miscibility of injected solvent. The optimum grid size was identified to use in simulation so that numerical discretization effect will minimize in the results. Then, in-depth investigations for merit and demerit of WAG displacement by different type of permeability heterogeneities such as permeability anisotropy, high permeability streaks (HKS), high permeability dolomite layer, matrix permeability and thin-dense stylolite layers were discussed. The investigations were carried out in terms of vertical sweep, displacement sweep, total oil recovery, gravity override, gas utilization, response time, hysteresis, un-contacted oil saturation, gas oil ratio (GOR) production. Finally, the economics of the process was also compared using highly heterogeneous and homogeneous reservoirs to understand economical impact of each WAG performance parameters. The advantages of this study are to provide better understanding about WAG performance and design in highly heterogeneous reservoirs for field applications, while disadvantages are that to quantify the permeability heterogeneity without uncertainty to see their impact on WAG displacement performance.

\section{Reservoir and simulation models descriptions}

The subject field is $32^{\circ} \mathrm{API}$ oil carbonate reservoir with average thickness, initial pressure and formation temperature in the range of 125-150 ft, 3850 psi at 7,550ft TVDSS and $210^{\circ} \mathrm{F}$, respectively. This field is divided according to permeability range into three reservoirs such as heterogeneous in east (20-60 mD), moderate heterogeneous in central (10-15 $\mathrm{mD})$ and tight homogeneous in west $(<3 \mathrm{mD})$. The east heterogeneous reservoir has high-frequency HKS in upper layers. This field has 7-45ft-thick six major layers (M1-M6) separated by $2-4 \mathrm{ft}$ thin stylolite (dense) intervals (D1-D5) in vertical direction as shown in Fig. 3. In addition, the dolomite layer (high permeability) is located in M5 porous layer at bottom of the reservoir.

The static models were constructed by extrapolating well log data across reservoir. The recent advance technologies such as 3D deconvolution and Radon demultiple were used to interpret faults, fracture, structure, HKS/dolomite mapping and rock typing (Sultan et al. 2005; Al Shateri et al. 2009; Yamamoto et al. 2012; Miyamoto et al. 2017). Reservoir facies, matrix permeability, initial water saturation were populated using sequential indicator simulation, sequential Gaussian simulation with co-kriggged with acoustic impedance and saturation height function derived from capillary pressure, respectively (Bushara et al. 1997; Venkitadri et al. 2005; Ghedan et al. 2006; Al-Suwaidi et al., 2010; Bachar et al. 2011; Al-ameri et al. 2011; Voleti et al. 2014). The matrix permeability was modeled independently of excess permeability (HKS and dolomite layers) using core-derived porosity-permeability transforms. The modeling of high permeability streaks (HKS) was done using dynamic well test data, while dolomite layer permeability modeling is done through porosity log by characterizing high dolomite content. The final permeability model was populated after integration of matrix and excess permeability (Bushara et al. 2002; Poli et al. 2009; Brantferger et al. 2012; Skene et al. 2014; Adeoye et al. 2015; Kohda et al. 2017; Ruelland et al. 2009). Then, history matching was carried out after construction of dynamic simulation model from static P50 model. The history matching process has been done by matching field reservoir pressure, wells shut-in bottomhole pressure, well water breakthrough, well water cut, field water breakthrough, field water cut production from simulation model (Branferger et al., 2011, 2012) as shown in Plot (a), Plot (b) and Plot (c) of Fig. 4. This subject large field is divided into three reservoirs based on their heterogeneities as explained above. The heterogeneous reservoir shows higher water cut in some wells due to high permeability streaks as shown in plot (a) of Fig. 4, while homogeneous shows very low water cut as shown in plot (b) of Fig. 4.
Fig. 3 Porous and stylolite layers vertical representation with average petro-physical properties of each porous layer of subject field

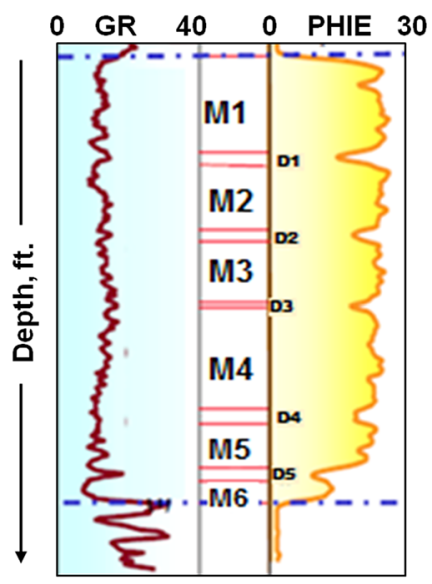

Avg. PHIE (Range)

$\%$

$\begin{array}{llll}19 & (0.01-728) & 23(0.001-35) \\ 23 & (0.1-1100) & 25 & (4-35) \\ 23 & (0.06-8100) & 25 & (8-36) \\ 9.4 & (0.04-340) & 24.5(8-35) \\ 7 & (0.01-126) & 22 \quad(2-34) \\ 1.5 & (0.01-116) & 15(0.2-32)\end{array}$

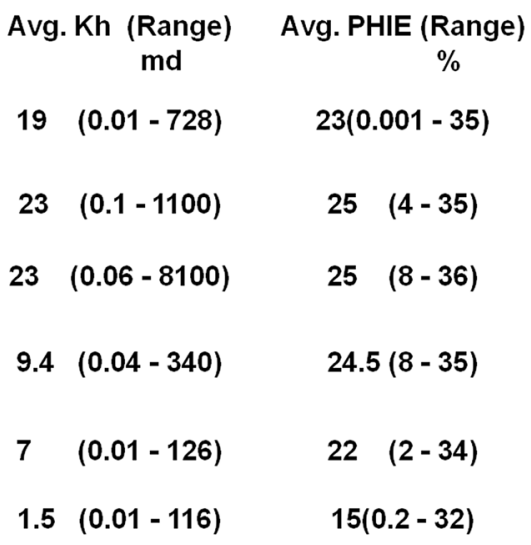



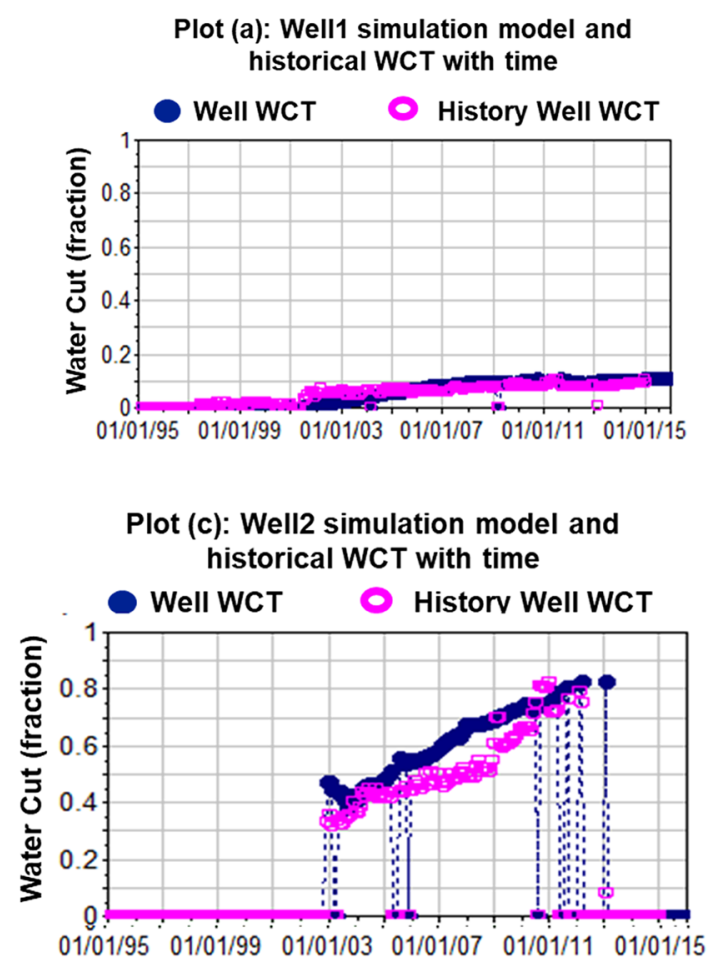

Plot (b): Well1 simulation model and historical bottom whole pressure (BHP) with time

Model BHP - Shut in Model BHP - History Shut in BHP

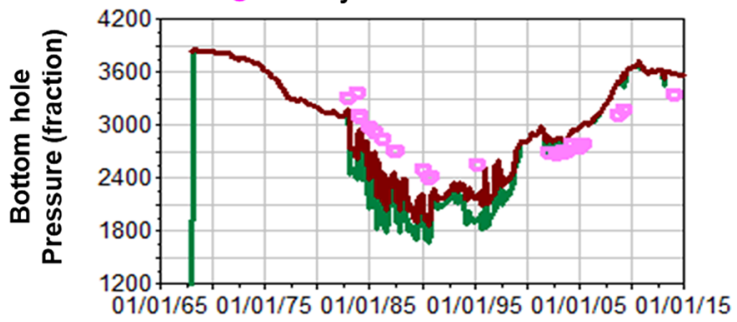

Plot (d): Well2 simulation model and historical bottom whole pressure (BHP) Model BHP Shut in Model BHP

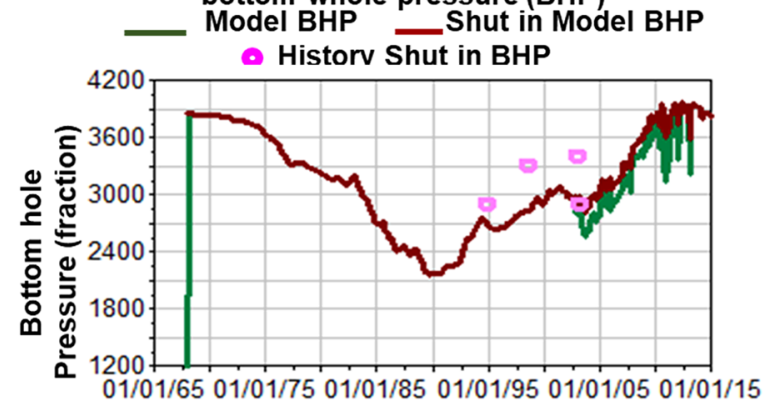

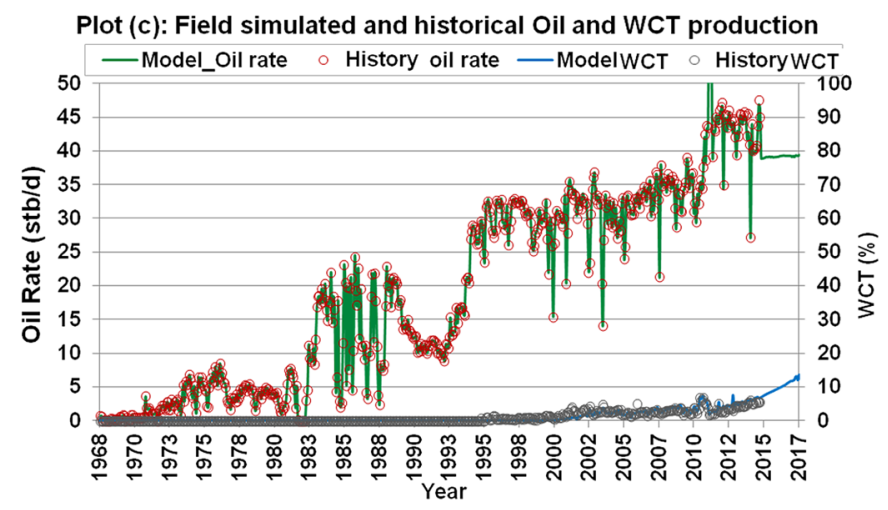

Fig. 4 History matched profile of oil rate, water cut and pressure for wells and field

Overall this large field (integrated both type reservoirs) shows very low water cut $\sim 10 \%$ after history match as shown in plot (c) of Fig. 4.

The fine-gridded 3D sector of synthetic as well as realfield models of homogeneous and heterogeneous reservoirs was constructed as shown in Fig. 5 and Fig. 6. Real-field simulation sector models of $1 \mathrm{~km} * 3 \mathrm{~km}$ area (heterogeneous reservoir) and $500 \mathrm{~m} * 3 \mathrm{~km}$ area (homogeneous reservoir) were cut directly from full-field history matched model, while synthetic simulation models $(1 \mathrm{~km} * 3 \mathrm{~km}$ area for both homogeneous and heterogeneous reservoirs) were generated by populating the average geological properties using a geological concept.
The 23 high-graded PVT samples of the field were used to tune equation of estate (EoS) model. The 9-component tuned unified EoS models as shown in Fig. 7 matched all the conventional and special PVT data. The calculation steps used to build PVT 9 component tuned Eos PVT model as: fluid component properties; plus fraction characterization; multi-contact miscibility calculations and ternary diagram generation; flash, saturation and envelop calculations; recombination and constant composition expansion calculations, differential liberation and constant volume depletion; separator; and swelling tests. This unified EoS model was used in composition simulation, which provide reliable results in EOR development options such as gas injection or WAG. The sector model 


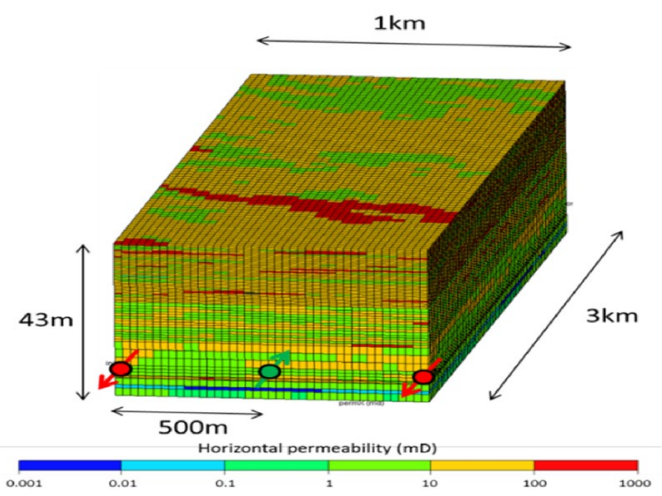

(a) Heterogeneous Model

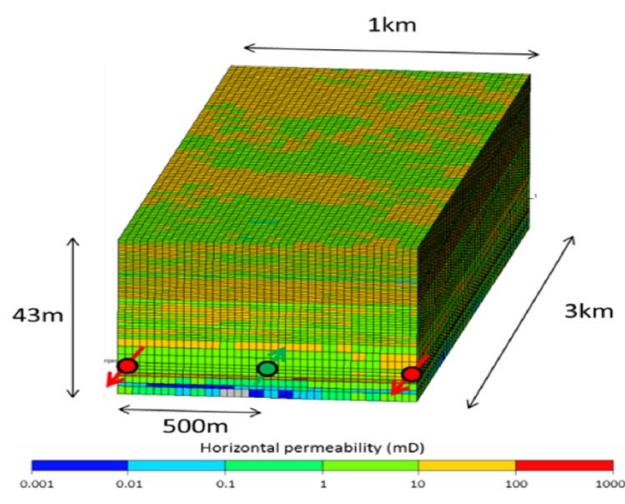

(b) Homogeneous Model

Fig. 5 3D Synthetic models

\section{Homogeneous Reservoir}

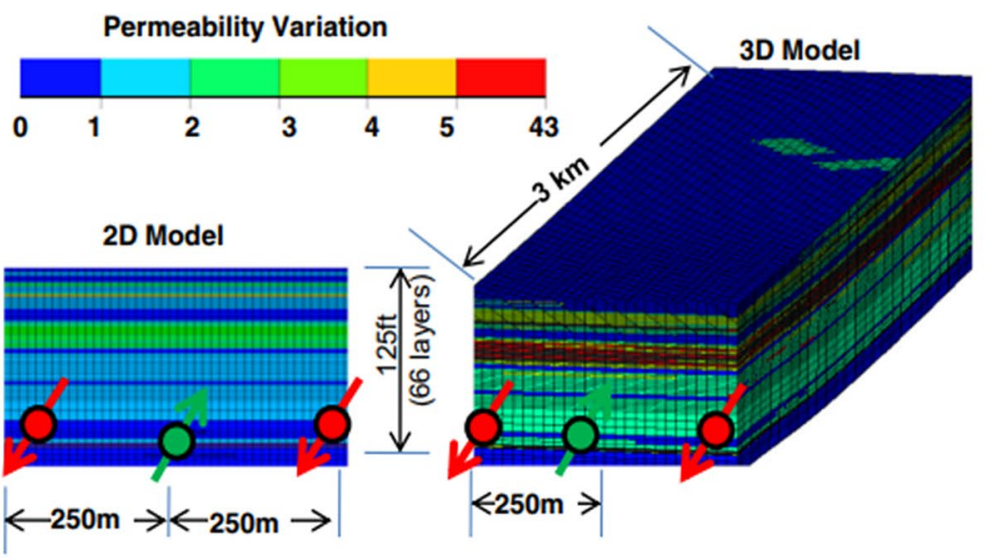

Heterogeneous Reservoir

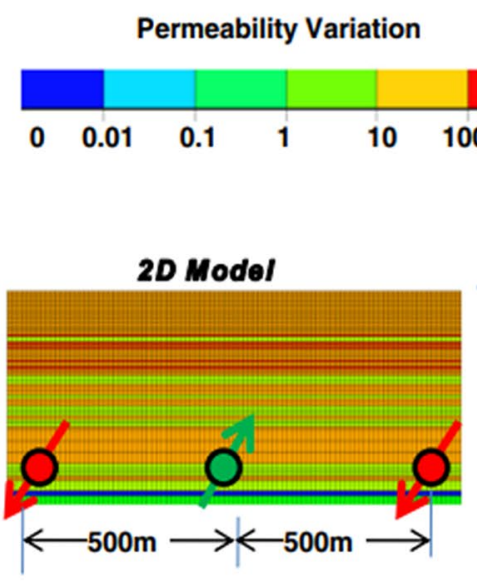

00
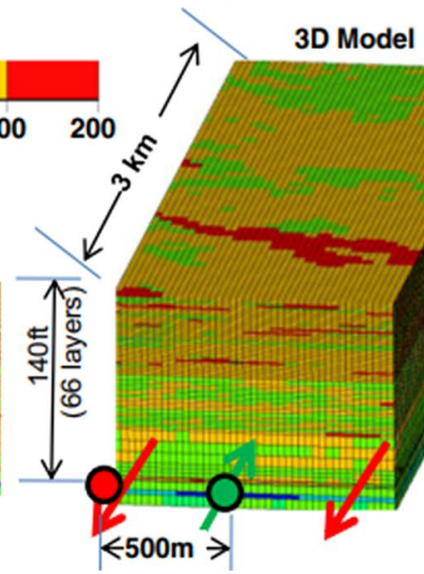

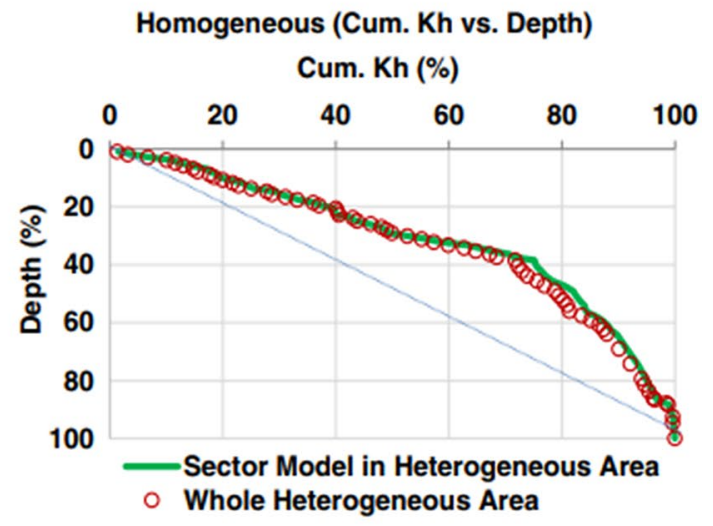

- Whole Heterogeneous Area

Heterogeneous (Cum. Kf vs. Depth)

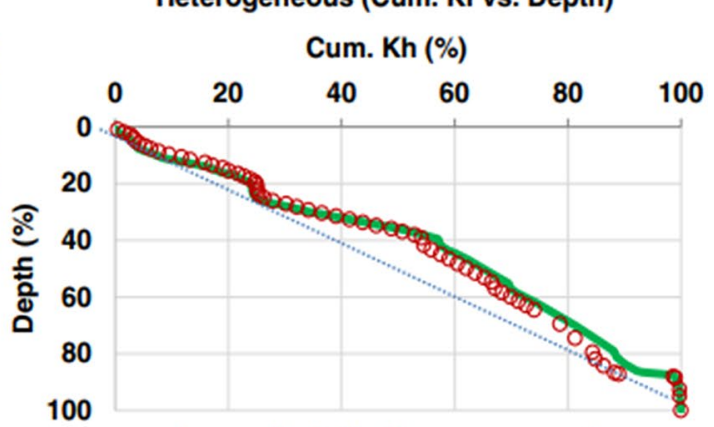

Sector Model in Homogeneous Area - Whole Homogeneous Area

Fig. 6 3D actual sector models 
9 Component tuned Equation of Estate (EoS)

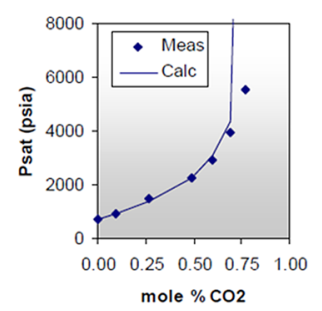

\section{Swelling Test}
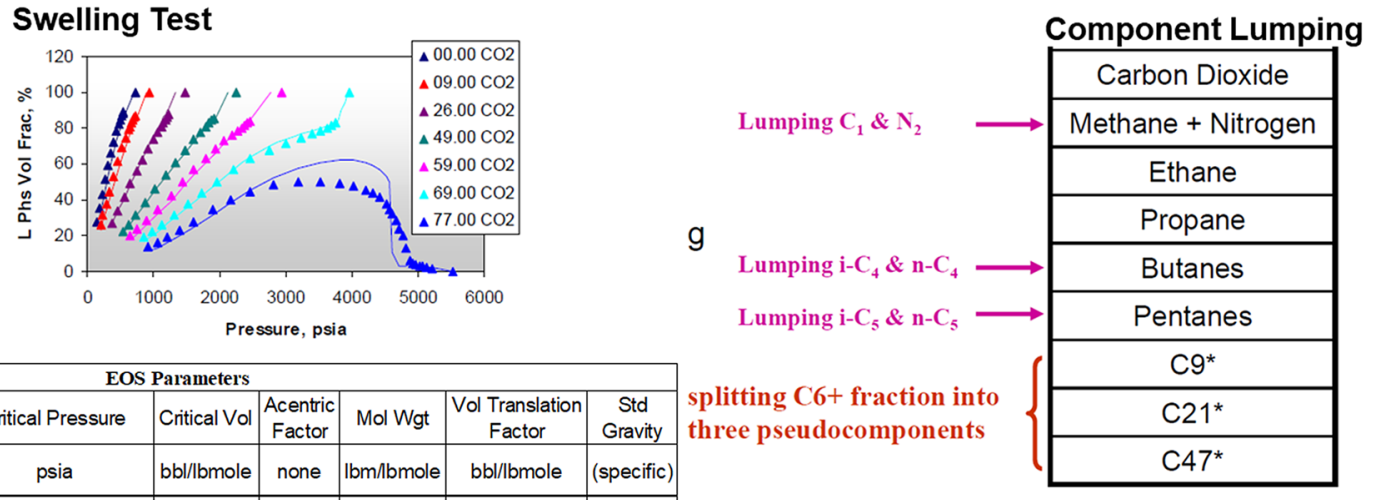

\begin{tabular}{|c|c|c|c|c|c|c|c|}
\hline \multicolumn{8}{|c|}{ EOS Parameters } \\
\hline $\begin{array}{c}\text { Compo } \\
\text { nents }\end{array}$ & Critical Temp & Critical Pressure & Critical Vol & \begin{tabular}{|c|} 
Acentric \\
Factor \\
\end{tabular} & Mol Wgt & $\begin{array}{c}\text { Vol Translation } \\
\text { Factor }\end{array}$ & $\begin{array}{c}\text { Std } \\
\text { Gravity }\end{array}$ \\
\hline & $\mathrm{F}$ & psia & bbl/lbmole & none & Ibm/lbmole & $\mathrm{bbl/lbmole}$ & (specific) \\
\hline $\mathrm{CO}_{2}$ & 87.908 & 1070.757 & 0.266 & 0.225 & 44.010 & 0.004 & 0.818 \\
\hline $\mathrm{C} 1+\mathrm{N} 2$ & -116.410 & 673.077 & 0.288 & 0.013 & 16.043 & 0.012 & 0.300 \\
\hline $\mathrm{C} 2$ & 90.104 & 708.351 & 0.419 & 0.099 & 30.069 & 0.011 & 0.356 \\
\hline C3 & 206.150 & 617.383 & 0.571 & 0.152 & 44.096 & 0.013 & 0.508 \\
\hline $\mathrm{C}^{*}$ & 298.448 & 545.581 & 0.724 & 0.197 & 58.122 & 0.014 & 0.579 \\
\hline$C 5^{*}$ & 379.273 & 487.144 & 0.877 & 0.241 & 72.149 & 0.011 & 0.628 \\
\hline $\mathrm{Cg}^{*}$ & 727.733 & 383.356 & 1.462 & 0.368 & 125.512 & -0.030 & 0.791 \\
\hline $\mathrm{C} 21^{*}$ & 1085.364 & 171.588 & 3.285 & 0.799 & 287.880 & -0.489 & 0.903 \\
\hline $\mathrm{C} 47^{\star}$ & 1402.119 & 75.482 & 7.493 & 1.548 & 660.294 & -1.951 & 0.991 \\
\hline \multicolumn{8}{|c|}{ Binary Interaction Parameter Coefficients for the Nine Component EoS } \\
\hline & Components Group1 & Components Group2 & A & B & C & & \\
\hline & C6+ fractions & C1 & 0.0122 & 0.1023 & 0.0000 & & \\
\hline & C6+ fractions & $\mathrm{CO} 2$ & 0.0950 & 0.0700 & 0.0000 & & \\
\hline
\end{tabular}

MMP from Tuned EoS

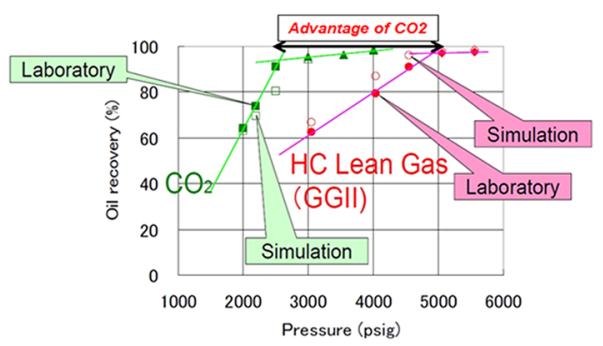

Fig. 7 Nine-component tuned equation of state (EoS) used for PVT in the simulation models

pressure maintains slightly above initial reservoir pressure (4200psi). The injectors keep at boundaries of sector models to avoid influence of adjacent producing pattern. The maximum bottom-hole injection pressure (5500psi) of each injector is kept below fracture pressure. The grid size optimization had been done using several simulation sensitivities. Finally optimum grid size $10 \mathrm{~m} * 10 \mathrm{~m}$ (i.e., below this grid size not significant impact of oil recovery and breakthrough) was used in all subsequent simulations. The tapered WAG ratio provides high oil recovery with efficient gas injection; therefore, it will be used in all subsequent simulation sensitivities for miscible WAG displacement.

Any hydrocarbon-bearing reservoir has unevenly distribution of interconnection between the pores due to nonuniformity in pore size of the rock, which results in heterogeneities and complex fluid flow behavior in the reservoir. The quantification of permeability heterogeneities is important before to see its impact on WAG displacement. The interpretation of dynamic data (such as production injection, ILT, PLT, downhole sampling, core flood, pressure test) can provide quantification of permeability heterogeneity at some extent, However, uncertainty in quantification of permeability heterogeneities is always there in subsurface geological environment. For example, the frequency of high permeability streaks and baffles due to tight stylolite layers is highly uncertain in cramp carbonate reservoirs. The reservoir learning/understanding of geological uncertainty is continued until end life of the reservoirs.

The carbonate reservoir heterogeneities depend mainly on depositional environments (diagenetic processes) such as cementation, solution, precipitation, dolomitization, dissolution, compaction and recrystallization of their minerals. These depositional environments create different shapes, size and origins of the pores, which results in unevenly distribution of permeability and porosity due to induced complex pore distribution (Akbar et al. 1995; 2000). The most of the heterogeneous reservoirs have different types of permeability heterogeneities like HKS, dolomite layer, stylolite layers, fractures, faults, vugs and baffles. Therefore, understanding the degree of fluid movement communication between different layers is crucial for WAG displacement due to uncertainty of permeability heterogeneity of the reservoir. The stratification and heterogeneity in the reservoir can affect on various parameters such as solvent miscibility with oil, injectivity, mobility ratios, injected fluid conning, relative permeability, injected fluid channeling and capillary pressure in WAG displacement process (Torabi et al. 2010; Dawe et al. 2011). The WAG displacement performance is severely affected by heterogeneity due to viscous fingering from different mechanisms (i.e., spreading, splitting, shielding and coalescence) (Brock and Orr Jr, 1991). Reservoir heterogeneities effect on WAG efficiency has been recognized by previous work notably by Virnovsky et al. 
(1996) and Surguchev et al. (1992a, b) due to impact on the stability of displacement front. The gas fingering and early breakthrough were observed mainly due to fractures and high permeable layers in WAG displacement (Xu et al. 2020), while the solvent channeling also results from high permeability layers, which reduces displacement efficiency and storage of the injected solvent (Wu et al. 2004). The horizontal flow is influenced by dispersion, viscous, capillary and gravity forces in vertically communicating porous strata (Rogers and Grigg 2000). The distributions of permeability and gravity segregation (flow rate, viscosity and fluid densities) have highest influence on optimum WAG ratio (WU et al. 2004). In addition, the permeability (high and low) layers control the injectivity of water and gas in WAG displacement (Surguchev et al. 1992a, b). Reservoir stratification may strongly affect gas or WAG displacement process as displacement fronts move according to the permeability of each layer (Sanchez 1999). Therefore, increasing the permeability contrast between layers results in faster GBT and poor oil sweep in WAG displacement process because most of the injected solvent displaces the oil from high preamble layers (Christensen et al. 2001; Masalmeh et al. 2010; AlAli et al. 2011). The loss of miscibility and early deterioration of solvent slug can be happened due to transverse dispersion by crossflow between differing permeability layers. However, if there is no crossflow between these layers, most of the portion of solvent slug passes through high permeability layers, which results in loss of miscibility in low permeability layers due to availability of insufficient solvent slug (Holm 1976). If the high permeable layers are present in the bottom part of the reservoir, then the areal sweep efficiency is higher due to favorable gravity effect, i.e., controlled the flow path by formation deposition sequence of the reservoir; therefore, WAG process delays in GBT and increases oil recovery (Summapo et al. 2013). However, the presence of high permeability streaks typically on top of reservoir leads to water and gas channeling, resulting in early WBT/ GBT (Sorbie and Walker, 1988; AlAli et al. 2011). This causes instability of flood front and creates disappearance of the miscible bank and large amount of oil un-swept results in low oil recovery. The permeability anisotropy ratio $\left(\mathrm{K}_{\mathrm{v}} / \mathrm{K}_{\mathrm{h}}\right)$ has a significant impact on hydrocarbon recovery, crossflow, different forces (viscous, capillary, gravity and dispersive), water or gas coning, well productivity, well testing, reservoir management and reservoir development strategy in WAG displacement (Landrum and Crawford, 1960; Kulkarni, 2003; Masalmeh et al. 2010; Mohamed et al. 2011). The deposition of thin shale or stylolite layers causes the difference in vertical and horizontal permeability. However, low $\mathrm{K}_{\mathrm{v}} / \mathrm{K}_{\mathrm{h}}$ results in high oil recovery as fluid behavior is less dominated by gravity segregation (Zahoor, 2011; Rogers and Grigg, 2000). The higher $\mathrm{K}_{\mathrm{v}} / \mathrm{K}_{\mathrm{h}}$ results in perpendicular crossflow occur due to higher influence of dispersion and forces like gravity, capillary and viscous (Larsen and Skauge, 1998; Bunge and Radke; Lyons and Plisga, 2011). Therefore, in-depth investigations were carried out to understand negative and positive impact of permeability heterogeneity in WAG displacement process as below:

\section{Permeability heterogeneity impact on vertical sweep in WAG displacement}

Dawe et al. (2011) presented that permeability heterogeneity affects the capillary pressure between the displacing and displaced phase, which will impact on residual saturation and hydrocarbon recovery as well as the displacement patterns. The high permeability streaks (HKS) present in upper layers of the subject heterogeneous reservoir have a significant impact on the behavior of water displacement process. The injected water overrides toward the HKS and flooded upper layers selectively. In theory, the water in upper layers will slump down due to gravity; however, in the reservoir, the water is held in the upper layers against the gravity force due to the capillary force. Plot (a) of Fig. 8 shows water saturation cross section after several year water flooding. The plot (b) shows the capillary pressure curves of the HKS layer and matrix (non-HKS) layers with water saturation. The water saturation of the HKS layer $\left(\mathrm{S}_{\mathrm{w}} 1\right)$ is much higher than the water saturation of matrix layer $\left(\mathrm{S}_{\mathrm{w}} 2\right)$ at the same capillary pressure $\left(\mathrm{P}_{\mathrm{c}} 2\right)$ level, and this difference allows high water saturation to be held in upper HKS layer against the gravity force (Namba and Hiraoka, 1995). This 'capillary holding' phenomenon causes poor vertical sweep efficiency resulting in high remaining bypassed oil in lower layers. Therefore, plot (c) of Fig. 8 shows lower oil recovery due to poor vertical sweep in heterogeneous reservoir (with HKS in upper layer) compared to homogeneous reservoir. In the WAG displacement, the injected solvent will also follow the same path as water in the reservoir with HKS to reduce vertical sweep.

\section{Permeability heterogeneity impact on oil recovery in WAG displacement}

The WAG process leaves considerable bypasses residual oil in low permeable layers as the displacement front moves through highly permeable layers inside the stratified reservoir (Donaldson et al. 1989). Therefore, permeability heterogeneities impact was analyzed using 3D compositional numerical simulation. The reservoir models were constructed with all identical configurations and controls except actual reservoir permeability heterogeneities to see each heterogeneity impact on miscible WAG performance. The oil recovery relationship with HCPVI (hydrocarbon pore volume injection) for both actual and synthetic 3D sectors models is shown in Fig. 9 and Fig. 10, respectively. The oil

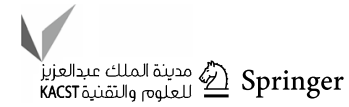


(a) Water saturation after several years water flooding in reservoir with HKS

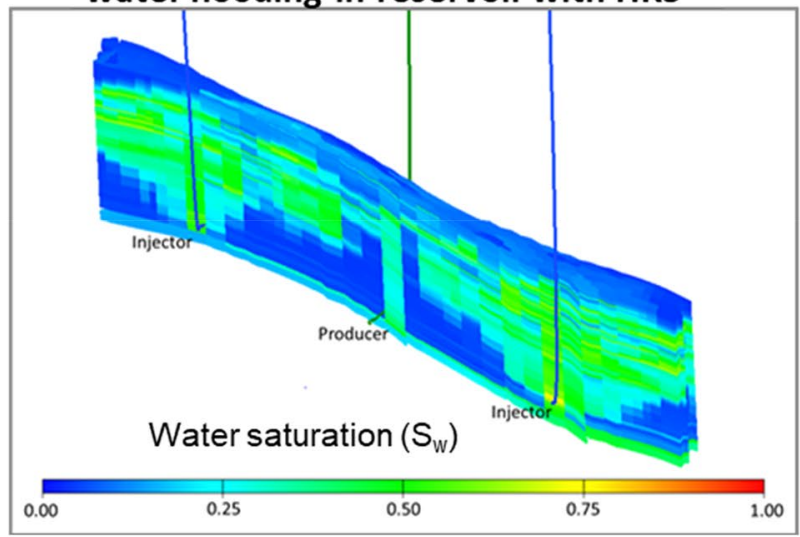

(b) Capillary pressure curve with and without high permeability streaks (HKS)
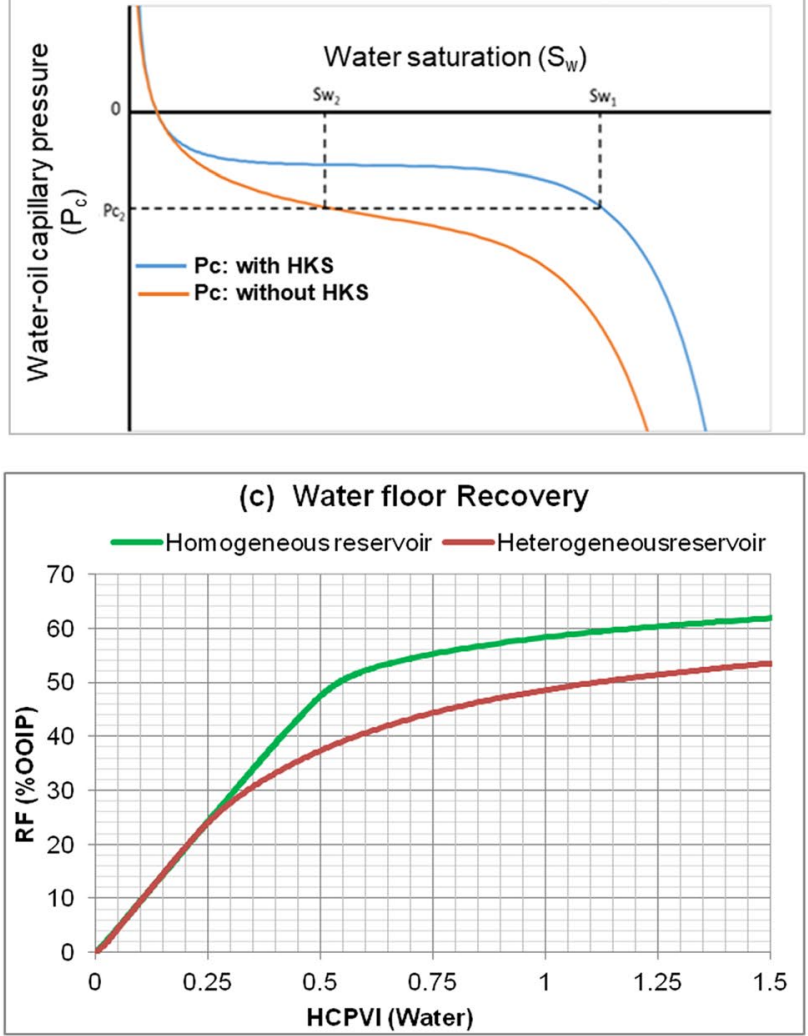

Fig. 8 Vertical sweep and oil recovery in water flood for homogeneous and heterogeneous reservoirs

recovery of water flood is significantly lower in heterogeneous reservoir compared to homogeneous reservoir as shown in Fig. 10 due to presence of thin HKS in the upper layers in synthetic models. The incremental oil recovery in WAG displacement over water flood is also lower in heterogeneous reservoir compared to homogeneous reservoir for both actual field and synthetic models as shown in Fig. 9 and Fig. 10.

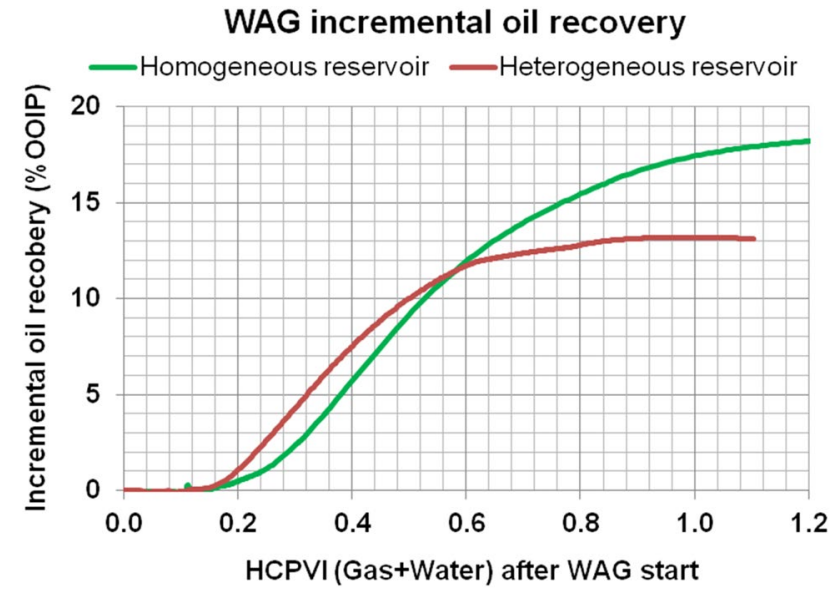

Fig. 9 Actual field 3D models oil recovery factors relationship with HCPVI in WAG displacement
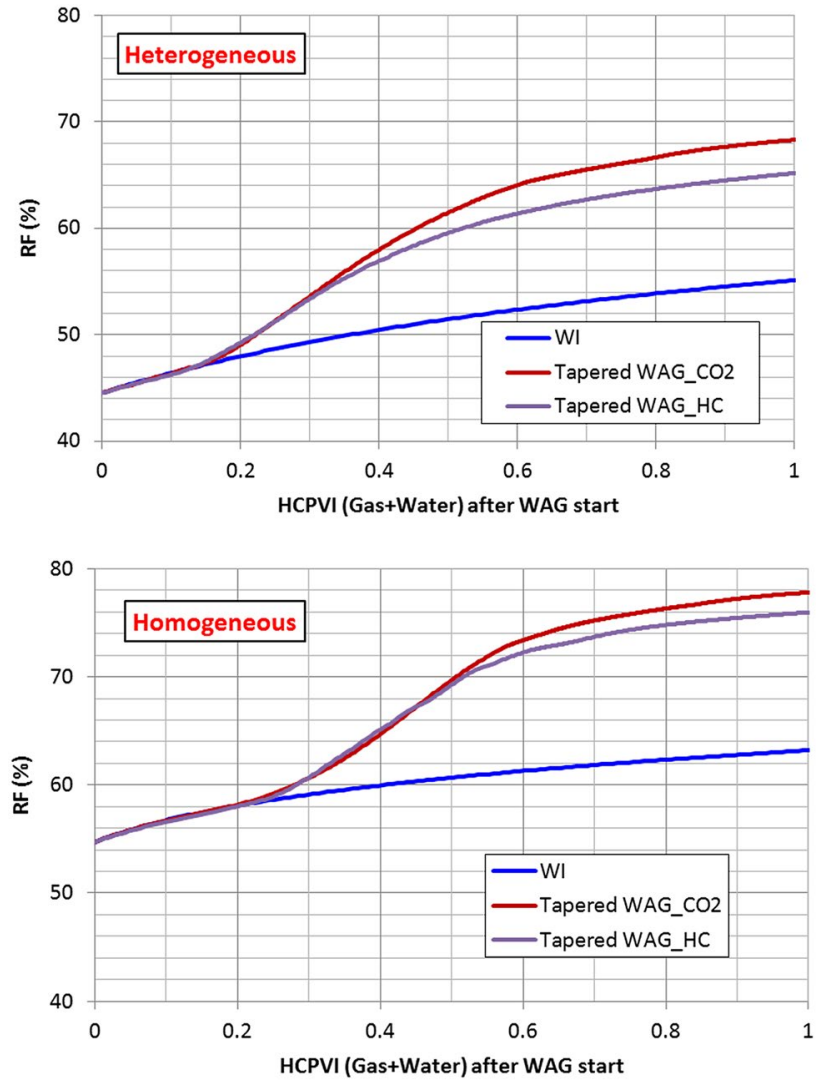

Fig. 10 Synthetic 3D models oil recovery factors relationship with HCPVI in WAG displacement

The WAG incremental oil recoveries expressed as percent of OOIP over the water injection case are about $17 \%$ in homogeneous reservoir and $13 \%$ in heterogeneous reservoir at 1 HCPVI. In actual field and synthetic 3D models, initially the heterogeneous reservoir shows faster incremental recovery, 
which is expected due to higher matrix permeability and high permeability streaks, while in later time (after 0.6 HCPVI) the incremental recovery is reduced compared to homogeneous reservoir as shown in Fig. 9 due to relatively piston-like uniform displacement in homogeneous reservoir.

The vertical permeability anisotropy will also affect oil recovery in WAG displacement process, which can be analyzed through vertical to horizontal permeability ratio $\left(\mathrm{K}_{\mathrm{v}} /\right.$ $\mathrm{K}_{\mathrm{h}}$ ). The $\mathrm{K}_{\mathrm{v}} / \mathrm{K}_{\mathrm{h}}$ effect on WAG performance can be easily explained through dimensionless gravity viscous number (G) in homogeneous reservoir, which is given by Fayers and Muggeridge (1990) and modified by Shook and Mitchell (2009) as below:

$G=\frac{1}{2 V} \frac{\Delta \rho g K_{h}}{\left(1-\frac{1}{M}\right) \mu_{o}} \frac{L}{H} \sqrt{\frac{K_{v}}{K_{h}}}$

where $\Delta \rho, \mathrm{V}, \mathrm{K}_{\mathrm{v}}, \mathrm{k}_{\mathrm{h}}, \mathrm{L}, \mathrm{H}, \mathrm{M}, \mathrm{g}$ and $\mu_{\mathrm{o}}$ are the density difference (displaced to displacing fluids), injected fluid velocity, vertical permeability, horizontal permeability, length, height, mobility ratio, gravitational constant and oil viscosity, respectively.

As per above Eq. (2), the gravity viscous number $(G)$ is proportional to square root of $\mathrm{K}_{\mathrm{v}} / \mathrm{K}_{\mathrm{h}}$ in WAG displacement for homogeneous reservoir, while the effect of $\mathrm{K}_{\mathrm{v}} / \mathrm{K}_{\mathrm{h}}$ on oil recovery in presence of permeability heterogeneities was found to be very complex in WAG displacement process due to change in flow direction of fluid movement in presence of different geological depositional environment (Giordane et al. 1985; Tidwell and Wilson 2000). The displacement efficiency reduces due to solvent channeling through HKS (Wu et al. 2004), while vertical permeability affects viscous, gravity, capillary and dispersive forces (Kulkarni 2003). The expected ultimate recovery (EUR) of oil was affected insignificantly by higher $\mathrm{K}_{\mathrm{v}} / \mathrm{K}_{\mathrm{h}}(\sim>0.1)$, while lower $\mathrm{K}_{\mathrm{v}} /$ $\mathrm{K}_{\mathrm{h}}(\sim<0.1)$ shows slower GBT, increases in oil recovery and reduces GOR production in both homogeneous and heterogeneous reservoir as shown in Fig. 11. In heterogeneous reservoir, the increase in $\mathrm{K}_{\mathrm{v}} / \mathrm{K}_{\mathrm{h}}$ (from 0.1 to 1 ) results in increase of oil acceleration and reduces in GBT due to the integrated effect of permeability heterogeneities (HKS in upper layers, high permeability dolomite layer at bottom) as shown in Fig. 11. Therefore, heterogeneous reservoir with very low $\mathrm{K}_{\mathrm{v}} / \mathrm{K}_{\mathrm{h}}$ shows better sweep efficiency; hence, it will be advantage in WAG displacement process.

\section{Permeability heterogeneity impact on solvent utilization factor in WAG displacement}

The solvent utilization factor (SUF) is represented as the injected gas required at standard conditions to produce one barrel of incremental oil from WAG process and can be defined as:

$S U F=\frac{(\text { Solvent }(\text { gas) injected }- \text { Solvent }(\text { gas }) \text { produced }), \text { Mscf }}{\text { Oil produced, } \mathrm{stb}}$

The GUF is important parameters to understand the project economic of WAG displacement process, which allow choosing the most economically advantageous option in mainly case of gas to be purchased and transported to the injection site. This factor indicates the amount of gas that is needed to recover a specified amount of oil. Plot (a) and plot (b) of Fig. 12 show HCPVI (hydrocarbon pore volume) of gas injection and solvent utilization factor (SUF) relationship
Fig. 11 Vertical permeability anisotropy impact on oil recovery (Khan and Mandal, 2019)

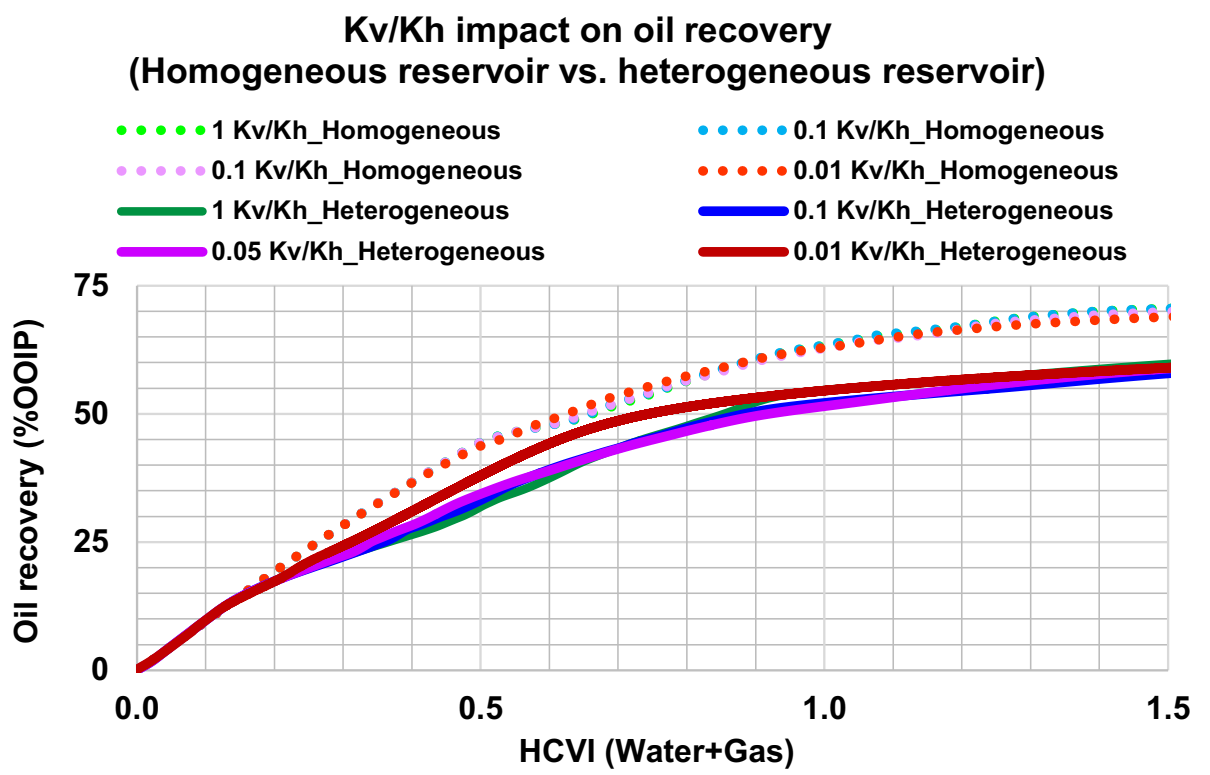

$\mathrm{Kv} / \mathrm{Kh}$ impact on oil recovery ... $0.1 \mathrm{Kv} / \mathrm{Kh} \_H o m o g e n e o u s$ -...0.01 Kv/Kh_Homogeneous $0.1 \mathrm{Kv} / \mathrm{Kh} \_H e t e r o g e n e o u s$ $0.01 \mathrm{Kv} / \mathrm{Kh} \_$Heterogeneous

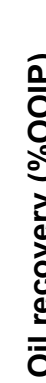


Plot (a): Amount of gas utilization

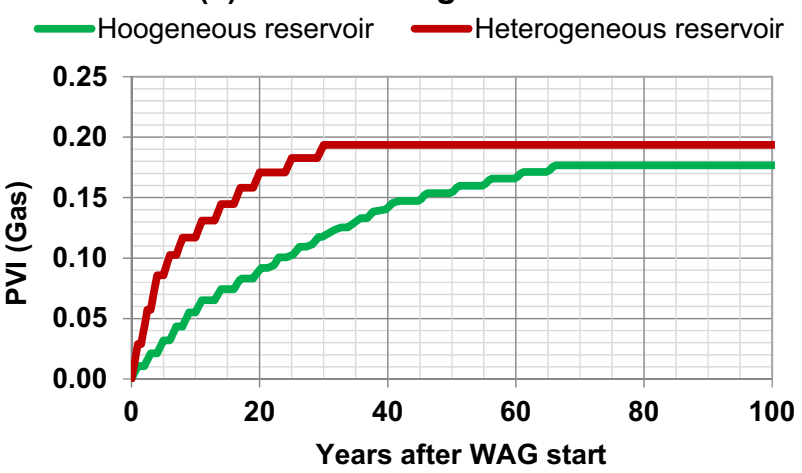

Plot (b): Gas utilization factor (UTF)

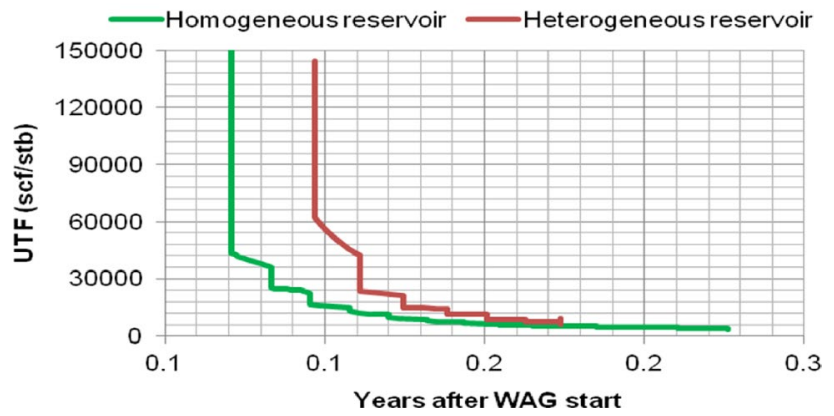

Fig. 12 Hydrocarbon pore volume gas injection and solvent utilization factor (UTF) relationship with time after gas injection starts in WAG process for homogeneous and heterogeneous reservoir

with time for homogeneous and heterogeneous reservoirs. The heterogeneous reservoir utilizes higher total gas requirement compared to homogenous reservoir as shown in plot (a) of Fig. 12. After expressing same information as solvent utilization factor (injection gas volume required for $1 \mathrm{stb}$ of incremental oil recovered), initially, the solvent utilization factor is lower in the homogeneous reservoir, while in later stage solvent utilization factor is nearly same for both homogeneous and heterogeneous reservoir as shown in plot (b) of Fig. 12. In the early stage, heterogeneous reservoir uses higher gas and provides faster oil recovery, but in later stage, homogeneous reservoir provides higher oil recovery with higher gas use due to piston-like uniform displacement sweep.

\section{Permeability heterogeneity impact on gas oil ratio (GOR), water cut (WCT) and WAG response time in WAG displacement}

The plots (a), (b) and (c) of Fig. 13 show the WAG incremental oil recovery (\% OOIP) over water flood, GOR and WCT production relationship with time after WAG starts in homogeneous and heterogeneous reservoirs. The response time for homogeneous and heterogeneous reservoirs was 8 years
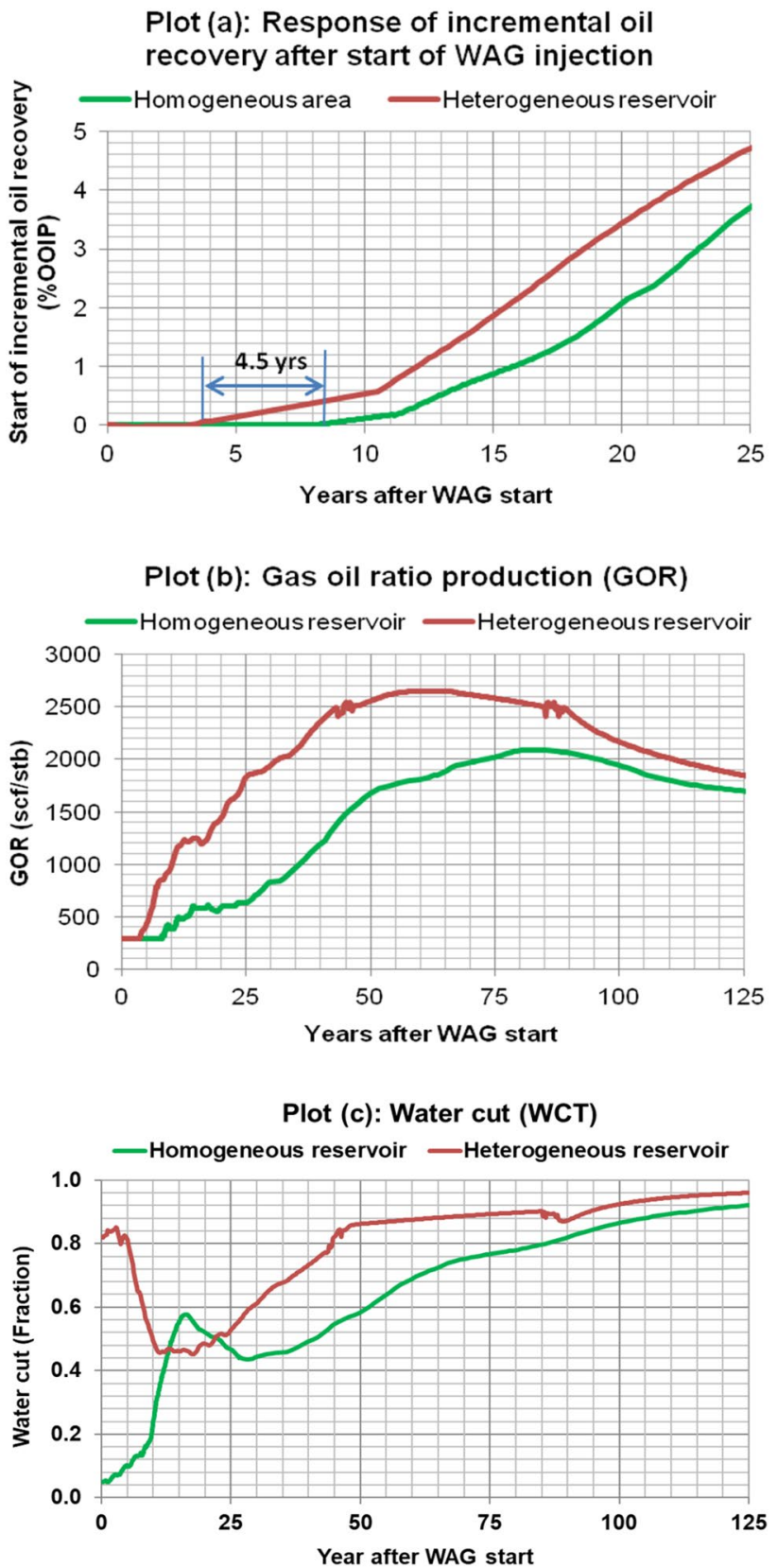

Fig. 13 WAG response time, GOR and WCT relationship with time after gas injection starts in WAG process for homogeneous and heterogeneous reservoirs

and 3.5 years, respectively. Initially, heterogeneous reservoir provides 4.5 years faster WAG response with higher oil acceleration with early gas breakthrough and higher GOR production compared to homogeneous reservoir as shown in plot (a) and (b) of Fig. 13, while in later time, oil incremental recovery was higher in homogeneous reservoir due to more uniform displacement front. Therefore, permeability heterogeneity decreases the ultimate oil recovery efficiencies, but it yields a rapid increase of oil recovery at the beginning 
of WAG displacement process. The faster gas movement in heterogeneous high permeability reservoir was observed, which is expected because initially higher pore volume gas is injected even though double well spacing compared to homogeneous reservoir. The EUR appears approximately to be insensitive to the timing of WAG implementation for both reservoirs. At the time of start of WAG, the water cut of heterogeneous reservoir is larger than homogeneous reservoir as WAG starts at $44.5 \%$ maturity in heterogeneous reservoir compared to $35 \%$ maturity in homogeneous reservoirs. The heterogeneous reservoir shows early water breakthrough and higher water cut production due to high matrix permeability as well as permeability heterogeneities (high permeability dolomite layers, high permeability streaks) compared to low matrix permeability homogeneous reservoir. Similarly, WCT was also higher in heterogeneous reservoir due to early WBT from HKS of upper layers as shown in plot (c) of Fig. 13.

Figure 14 compares the sweep efficiency between the heterogeneous and homogeneous reservoirs in 3D models at gas breakthrough time. The heterogeneous reservoir shows faster breakthrough and accelerates the oil production due to fingering; conversely, sweep in homogeneous model is uniform and advancing at a similar rate along the top and bottom due to a higher permeability dolomite layer in the bottom of the region.

Further, the impact of vertical permeability anisotropy was analyzed on GBT and GOR production using $\mathrm{K}_{\mathrm{v}} / \mathrm{K}_{\mathrm{h}}$ ratio. The homogeneous reservoir shows slower GBT and lower GOR production with very low $\mathrm{K}_{\mathrm{v}} / \mathrm{K}_{\mathrm{h}}(<0.1)$ due to viscous dominant flow (i.e., gravity number $<1$ ) as shown in Fig. 15, while the GOR production increases with faster
Fig. 14 Gas volumetric sweep efficiency comparison

Fig. 15 Vertical permeability anisotropy impact on GOR production (Khan and Mandal, 2019)

\section{(a) 3D Homogeneous Model}

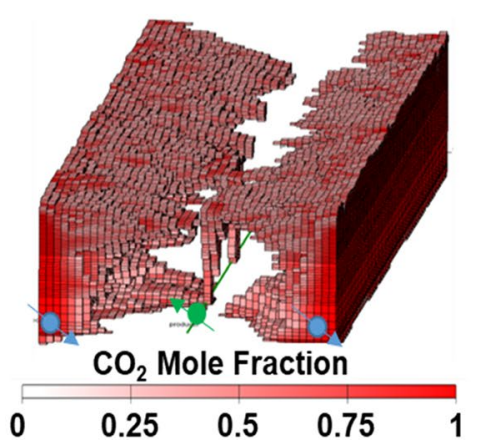

(b) 3D Heterogeneous Model

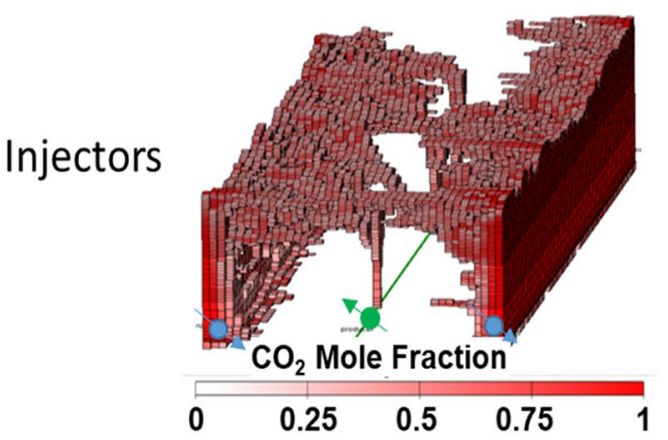

\section{$\mathrm{Kv} / \mathrm{Kh}$ impact on GOR production \\ (Homogeneous reservoir vs. heterogeneous reservoir)}

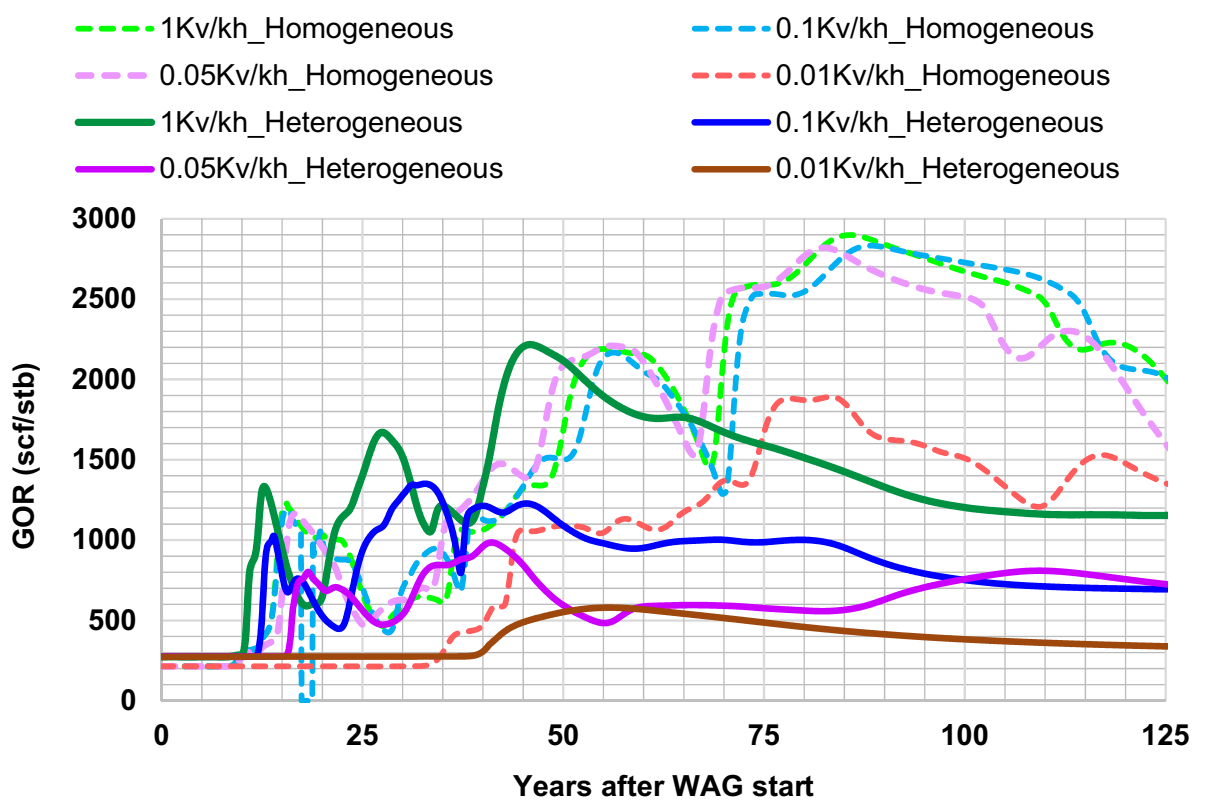


GBT when $\mathrm{K}_{\mathrm{v}} / \mathrm{K}_{\mathrm{h}}$ increases (from 0.1 to 1 ) in homogeneous reservoir due to viscous effect suppressed by gravity effect and start of gravity tongue (i.e., gravity number $>1$ ) as shown in Fig. 15. The heterogeneous reservoir shows very complex trend of GBT and GOR production due to presence of permeability heterogeneities. The presence of HKS in heterogeneous reservoir shows poor oil recovery and early GBT or/and WCT due to reduction of oil mobility as HKS response first. However, heterogeneous reservoir with very low $\mathrm{K}_{\mathrm{v}} / \mathrm{K}_{\mathrm{h}}(<0.1)$ shows increase in WAG incremental oil recovery with delayed GBT and low GOR production as the heterogeneity (HKS) effect is suppressed by viscous-dominated effect as shown in Fig. 15, while as $\mathrm{K}_{\mathrm{v}} / \mathrm{K}_{\mathrm{h}}$ increases (from 0.1 to 1 ), the impact of $\mathrm{K}_{\mathrm{v}} / \mathrm{K}_{\mathrm{h}}$ is very complex as flow performance is governed by permeability heterogeneity. The heterogeneous reservoir shows oil acceleration, early GBT as increase in $\mathrm{K}_{\mathrm{v}} / \mathrm{K}_{\mathrm{h}}$ (from 0.1 to 1 ) due to combined effect of HKS, dolomite layer permeability, matrix permeability and increasing in gravity as shown in Fig. 15.

\section{Permeability heterogeneity impact on hysteresis in WAG displacement}

In WAG displacement, the gas phase is trapped (immobile gas saturation in the porous rock) during water flood cycle after gas flood cycle. This effect creates significant hysteresis in drainage and imbibition processes of WAG displacement, which reduces the relative permeability of water phase in oil/mixed wet reservoirs (Land, 1968; Skauge and Aarra, 1993; Braun and Holland, 1995; Joekar-Niasar et al. 2013; Masalmeh et al. 2021; Sedaghatinasab et al. 2021). The relative permeability to wetting phase increases and to that of non-wetting phase decreases in imbibition cycle compared to drainage cycle; therefore, the relative permeability of phases depends on whether that phase saturation was obtained by approaching it from a higher or lower value. These phenomena arise hysteresis in relative permeability of phases (Larsen \& Skauge, 1998; Skauge and Larsen, 1994). Hence, the relative permeability of phases obtained from classical techniques might not be applicable correctly to WAG displacement process due to hysteresis (DiCarlo et al. 2000; Fenwick and Blunt, 2013). At least, two sources by which hysteresis occurs in WAG displacement are (1) trapping of the non-wetting phase (gas); (2) advancing the contact angle of wetting phase (water) displacing a non-wetting phase (gas). Therefore, hysteresis in capillary pressure and wetting and non-wetting phase's relative permeability are important critical input parameters in compositional simulation to predict reliable miscible WAG floods performance. The amount of solvent injection perdition will be underestimated if hysteresis was not considered in WAG displacement.

The plots (a) and (b) of Fig. 16 represent the comparison of oil recovery (\% OOIP) and GOR production relationship with HCPVI with and without hysteresis for homogeneous and heterogeneous reservoirs. The simulation results show that heterogeneous reservoir has insignificant impact on oil recovery due to the presence of hysteresis in gas relative permeability $\left(\mathrm{K}_{\mathrm{rg}}\right)$, water relative permeability $\left(\mathrm{K}_{\mathrm{rw}}\right)$ and capillary pressure $\left(\mathrm{P}_{\mathrm{c}}\right)$. However, the presence of HKS in upper layers of heterogeneous reservoir shows more hysteresis dominant effect due to water/gas overrides through HKS and leaving un-contacted oil in lower layers as shown in Fig. 16. The low permeability homogeneous reservoir shows insignificant impact due to presence of hysteresis in gas relative permeability, while the oil recovery and GOR production reduce if there is no hysteresis in water relative permeability. Consequently, the oil recovery and GOR further reduce if there is no hysteresis in capillary pressure as represented in Fig. 16.

\section{Permeability heterogeneity impact on un-contacted oil saturation $\left(\mathrm{S}_{\text {orm }}\right)$ in WAG displacement}

In WAG displacement, gas injection half cycle provides more oil production (or oil recovery) due to lower interfacial tension between gas oil by gas invading oil trapped pores after the first water cycle, while water injection half cycle snaps off the gas bubbles at the pore throats, which create discontinuous oil phase due to local gas pressure fluctuations and capillary forces (Sohrabi et al. 2000). Therefore, generally, the major oil sweep is achieved from pores after few numbers of WAG injection cycles. The compositional simulation shows that the oil saturation near to injector will be as low (nearly to zero) as predicted by equation of state, but laboratory core flood observation indicates nonzero residual oil saturation $\left(\mathrm{S}_{\mathrm{orm}}\right)$. Hence, miscible gas injection overestimates oil recovery from simulation even though miscible core flood tests show rarely $100 \%$ recovery as well as field observations show bypassed oil in miscible gas injection process (McGuire et al. 2005; Stalkup, 1983). One example is shown in cross-sectional view of oil saturation in Fig. 17, and the simulation results indicate that some grids have very small oil saturation (i.e., theoretically almost zero) near to injector well after miscible gas floods, which will result in overestimate of the miscible benefit. Hiraiwa and Suzuki (2007) derived a method for incorporation of this laboratory-based residual oil saturation $\left(\mathrm{S}_{\text {orm }}\right)$ in compositional simulation. This proposed method maintains the prescribed residual oil using transport coefficient due to restriction of the excessive vaporization. Figure 17 shows WAG incremental recovery factor and solvent production/injection ratio relationship with HCPVI generated for heterogeneous and homogeneous reservoirs. The simulation results overestimated miscible WAG incremental oil recovery factor approximately 2-3 (\% OOIP) as shown in Fig. 17 for both heterogeneous and homogeneous reservoirs due to not 
Fig. 16 Hysteresis effect on oil recovery and GOR production in WAG displacement process
Plot (a): Hystresis impact on oil recovery (Homogeneous reservoir vs. Heterogeneous reservoir)

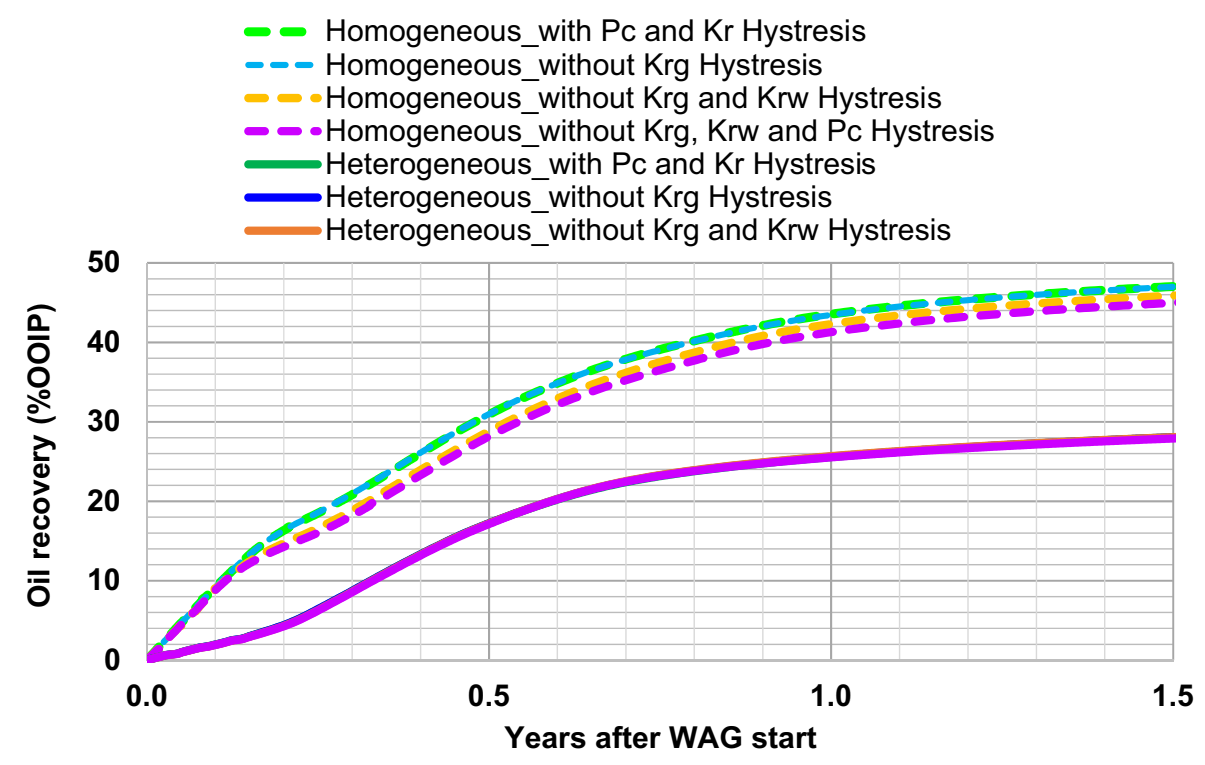

Plot (b): Hystresis impact on gas oil ratio (GOR) production (Homogeneous reservoir vs. Heterogeneous reservoir)

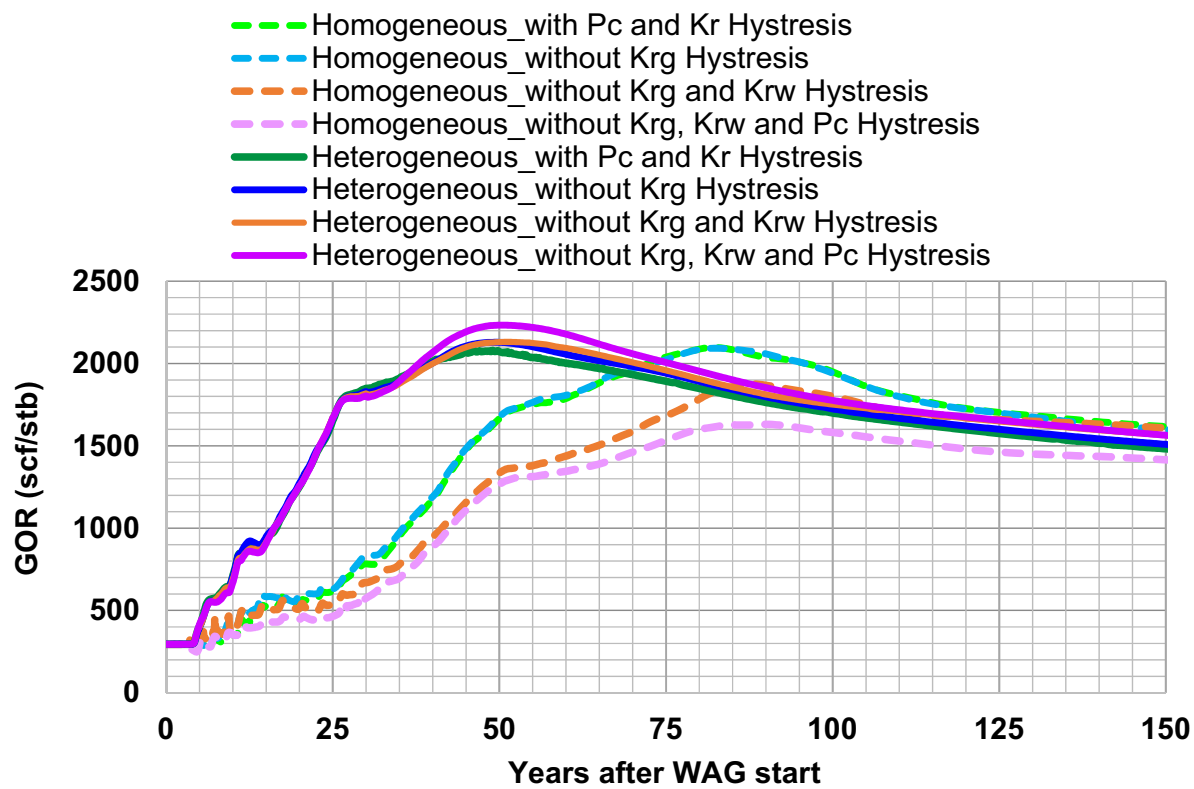

consideration of un-contacted oil saturation $\left(\mathrm{S}_{\text {orm }}\right)$, while laboratory shows $18 \% \mathrm{~S}_{\text {orm }}$.

\section{Permeability heterogeneity impact on gravity override in WAG displacement}

\section{By well spacing}

There are three forces affecting the gas behavior such as viscous, gravity and capillary forces. Hence, these forces dominant effects were analyzed due to well spacing and geological heterogeneity (matrix permeability, HKS layer

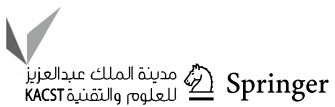


Cross-sectional view of oil saturation near to miscible gas injector

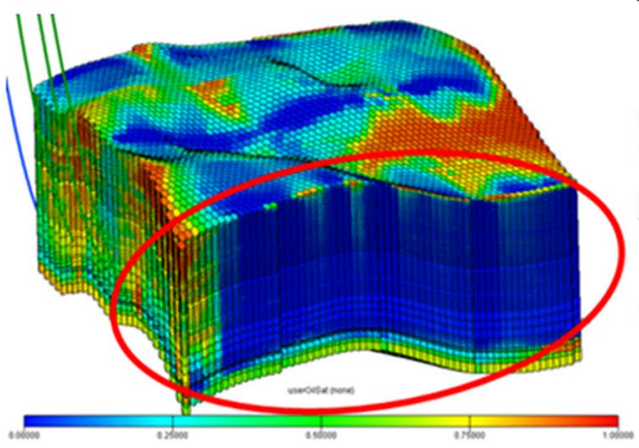

Oil recovery with and without $S_{\text {orm }}$ in heterogeneous reservoir

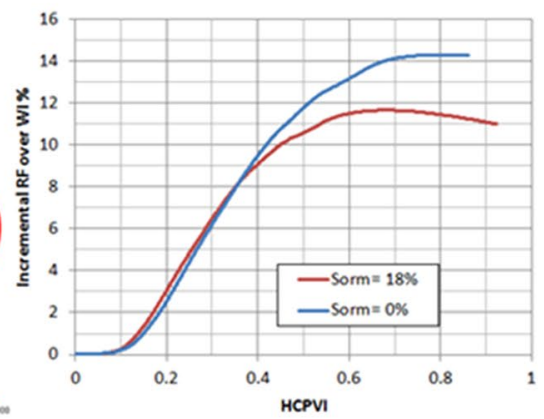

Oil recovery with and without $S_{\text {orm }}$ in homogeneous reservoir

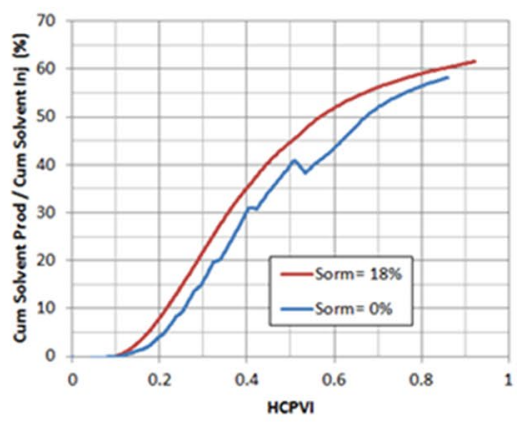

Fig. 17 Cross-sectional view of small residual oil saturation (almost zero) after gas flood; type curve with and without $\mathrm{S}_{\text {orm }}$ impact in heterogeneous and homogeneous reservoirs
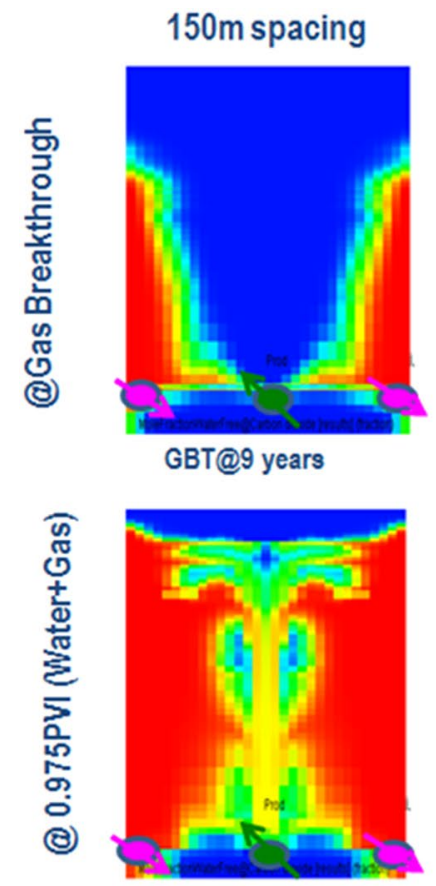

$250 \mathrm{~m}$ spacing

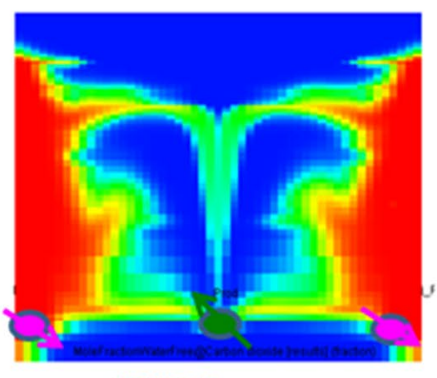

GBT@20 years

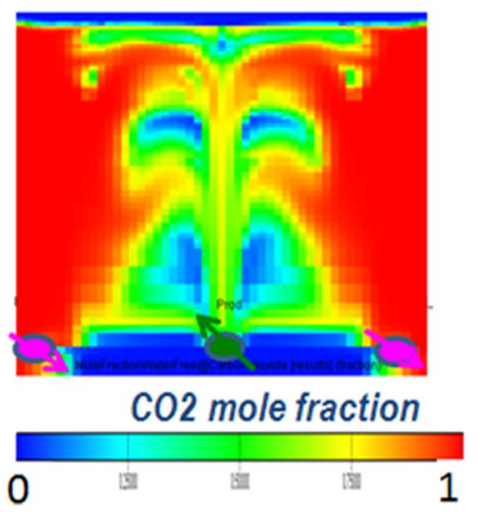

500 m spacing
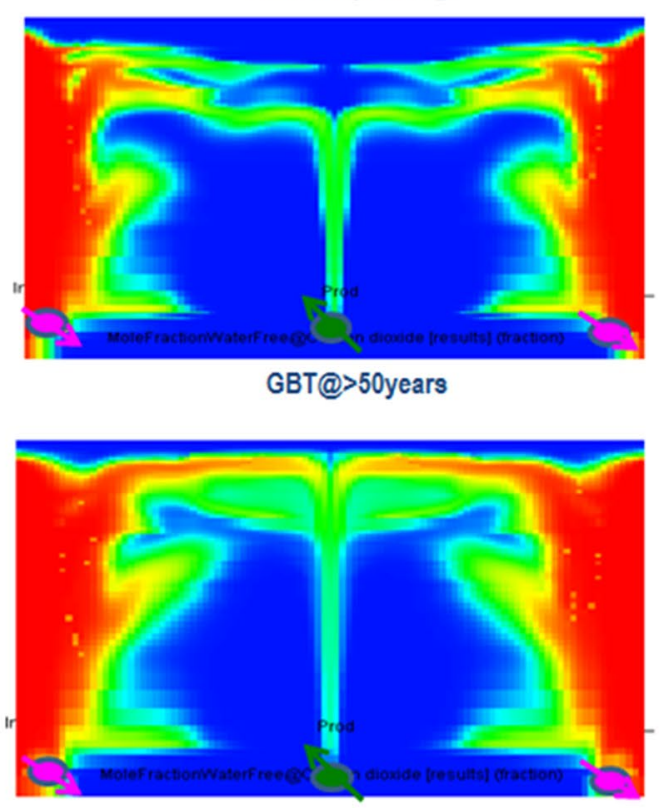

Fig. 18 2D cross-sectional view of $\mathrm{CO}_{2}$ gas front movement due to well spacing impact in low permeability homogeneous reservoir

and dolomite high permeability layer) for the evaluation of gas gravity override in miscible WAG displacement process.

Figure 18 and Fig. 19 show the cross-sectional view of $\mathrm{CO}_{2}$ gas movement at GBT and after GBT with different well spacing in homogeneous and heterogeneous reservoirs. Simulation model results show that wider well spacing provides more gas gravity override as shown in Fig. 18 and Fig. 19 as gravity force becomes more dominant than viscous force as well spacing increases between injector and producer. Hence, a lot of un-contacted oil will leave in the lower layers of both homogeneous and heterogeneous reservoirs. However, the tighter homogeneous 

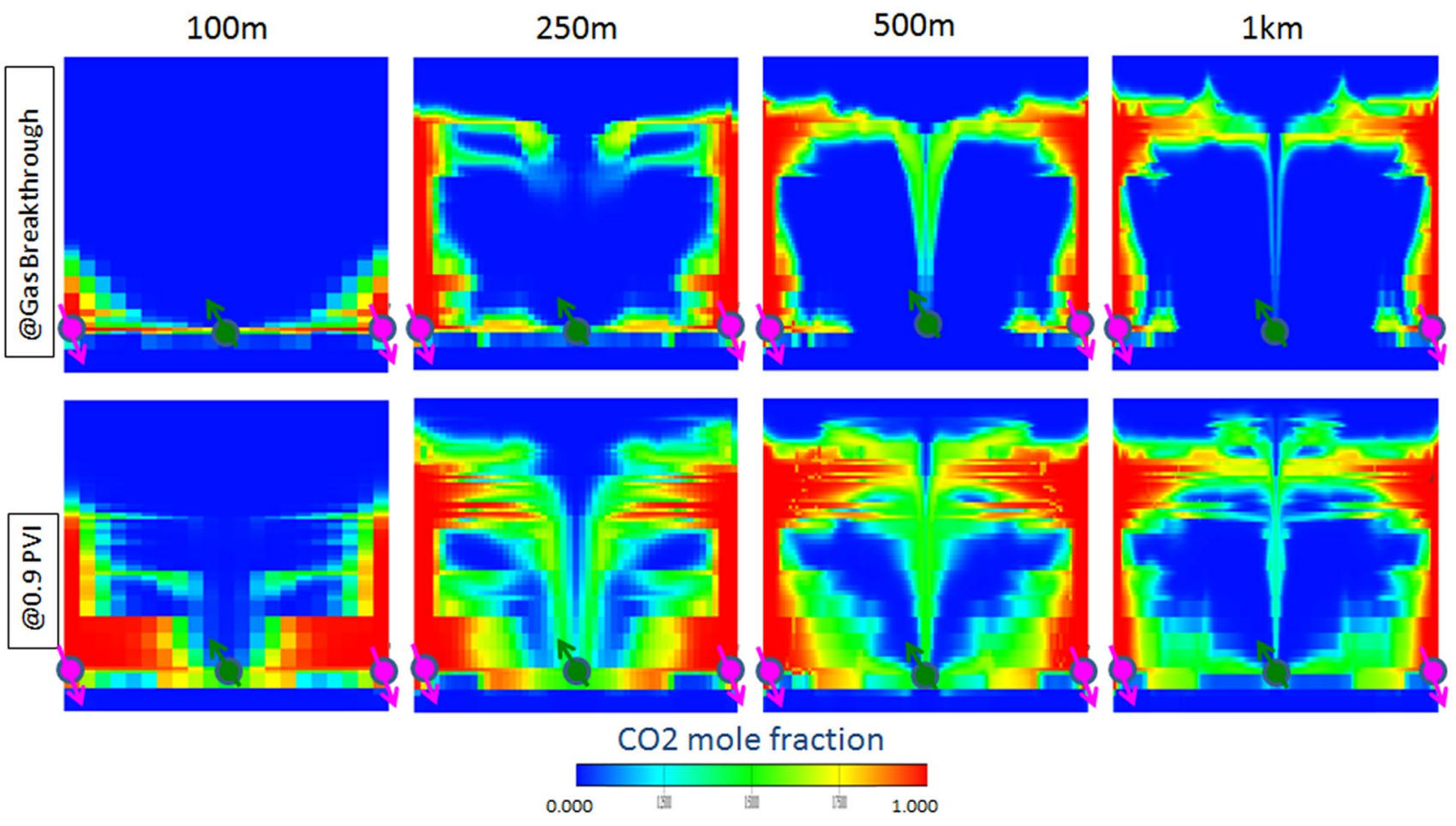

Fig. 19 2D cross-sectional view of $\mathrm{CO}_{2}$ gas front movement due to well spacing impact in high permeability heterogeneous reservoir with HKS

reservoir shows higher gas gravity overrides with wider well spacing compared to heterogeneous reservoir due to higher gravity force dominant over viscous force.

\section{By matrix permeability}

Lower horizontal permeability helps in improving longterm cumulative oil recovery, while the higher permeability adversely affects the production with higher cumulative water and gas production in WAG displacement process (Temizel et al. 2014). For the evaluation of matrix permeability impact on gas gravity override, simple mechanistic 2D models were developed with different permeabilities as low as in homogeneous reservoir (1md) and high as in heterogeneous reservoir (25md) with same well spacing. Figure 20 shows cross-sectional view of the shape of water and gas displacement front with different HCPVIs due to the effect of matrix permeability. The vertical waterfront movement is relatively uniform in low permeability case compared to high permeability case, which has conical shape type front movement toward the lower layer of the reservoir due to dominant gravity force that tends to move water toward the lower layers in high permeability reservoir, while the viscous force is relatively dominant in low permeability reservoir. In the gas injection cases, the GBT occurs from upper layers due to gas gravity override in high permeability case, while more uniform and higher vertical sweep has been observed in low permeability cases due to dominant effect of viscous in low permeability case.

\section{By high permeability streaks (HKS)}

The gas channeling becomes more severe in WAG displacement for stratified heterogeneous reservoir, which has large permeability variation and longitudinal correlation lengths between the zones of the reservoir (Araktingi et al. 1990). If HKS is present at the bottom of the heterogeneous reservoir, then areal sweep efficiency will be higher due to favorable gravity segregation, i.e., reservoir fluids are controlled by formation deposition sequence; hence, WAG process delays in GBT and increasing oil recovery. However, the presence of high permeability streaks typically on top of reservoir leads to water and gas channeling, which results in early WBT and GBT. This phenomenon results in large amount of unswept oil due to disappearance of the miscible bank as developed by the flood front instability. The viscous fingering also results in early GBT even though in homogeneous reservoir, which has less impact of gravity (Fayers and Muggeridge, 1990; Christensen et al. 2000). Figure 21 shows the cross sections of the $\mathrm{CO}_{2}$ mole fraction in the tapered $\mathrm{CO}_{2}$ WAG simulation case for heterogeneous and homogeneous models. Gas gravity override occurred in both models, but the heterogeneous model shows more gas override in early stage due to the HKS in upper layers. This gravity override

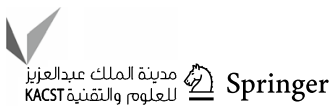



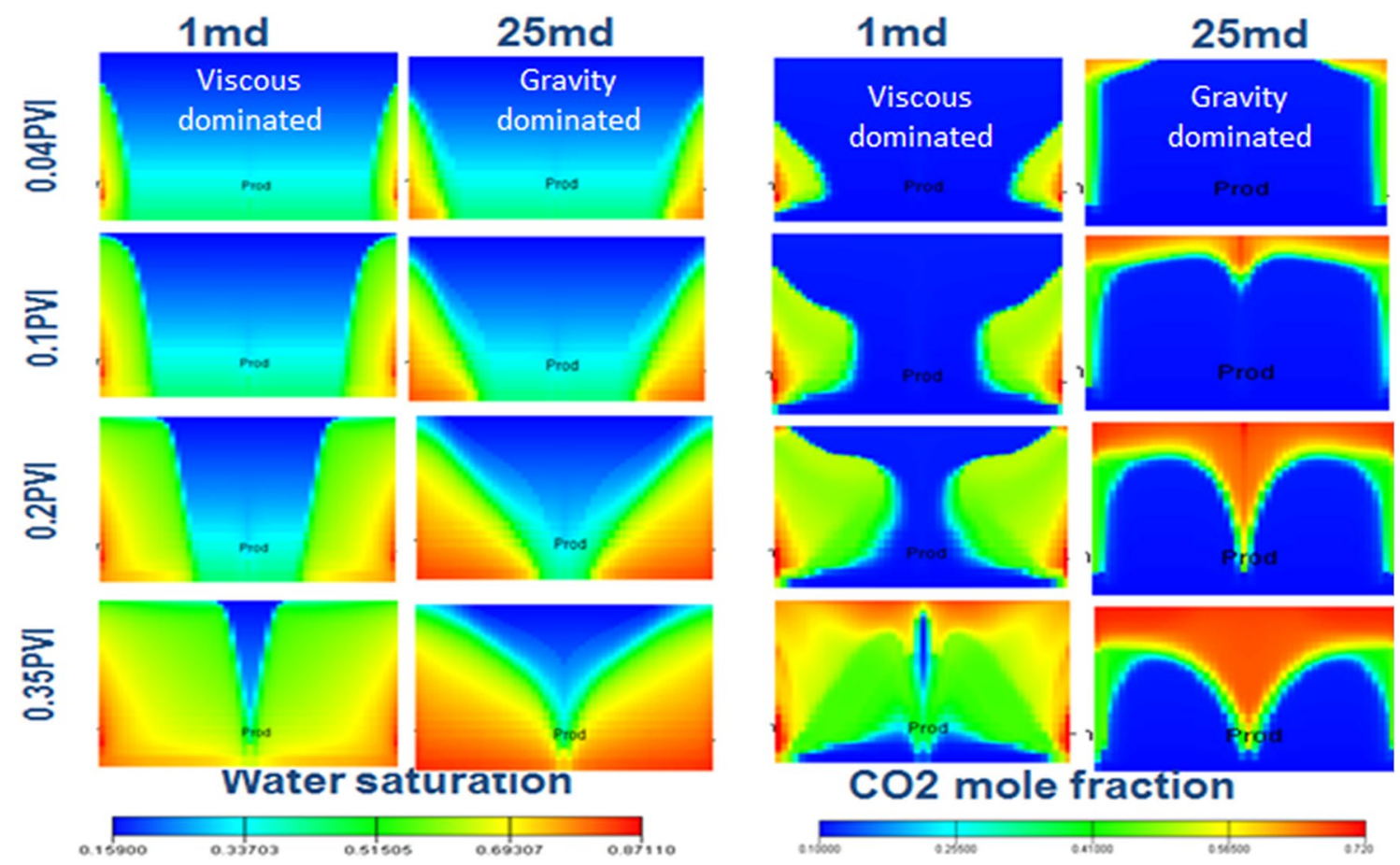

Fig. 20 Matrix permeability impact on shape of water and gas front displacement

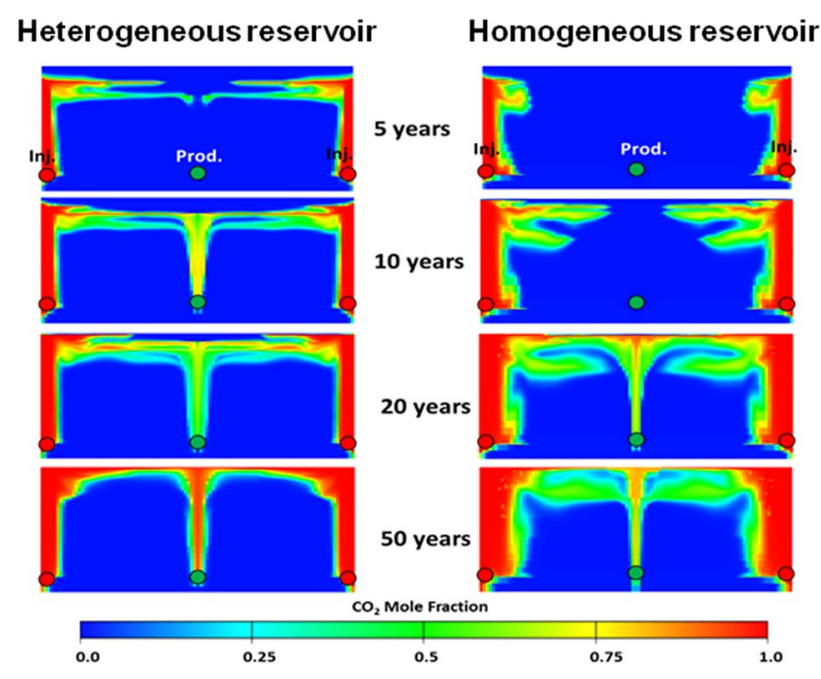

Fig. 21 Comparison of gas override for heterogeneous and homogeneous models

results in earlier GBT and faster oil acceleration in heterogeneous reservoir. However, finally, both models show similar level of gas override after long time gas injection and the ultimate oil recovery uplift is also similar.

\section{By integrated impact of HKS, dolomite layer permeability and matrix permeability}

In homogeneous reservoir, the gas moves upward and water moves downward due to their densities, while this effect will be more dominant in higher matrix permeability reservoir due to the increasing effect of gravity force over viscous force, while both gas and water may move upward due to capillary holding phenomena in presence of HKS in upper layers of the reservoir. In addition, water may move toward down and gas toward up due to higher gas mobility in presence of high permeability dolomite layer at bottom of the reservoir. However, this effect will be large in presence of both HKS in upper layer and high permeability dolomite layer at bottom of the reservoir. These effects show that the increasing permeability heterogeneities results in more significant gravity override in stratified reservoir (Cullick et al. 1993). Therefore, in the heterogeneous reservoir, the period of maximum possible constant rate reduces with the increase in permeability heterogeneities due to early gas breakthrough (GBT), while the oil acceleration with less expected ultimate oil recovery was observed due to arrival of large solvent and water slug toward the producer wells and leaving unswept oil at bottom of the reservoir. Therefore, permeability heterogeneities play strong influence on WAG displacement process. Figure 22 compares the 2D cross-sectional views of injected gas movement at different HCPVI (water and gas) 
Fig. 22 Cross-sectional view of on $\mathrm{CO}_{2}$ gas movement due to impact of matrix permeability, HKS and dolomite layer permeability in homogeneous and heterogeneous reservoir

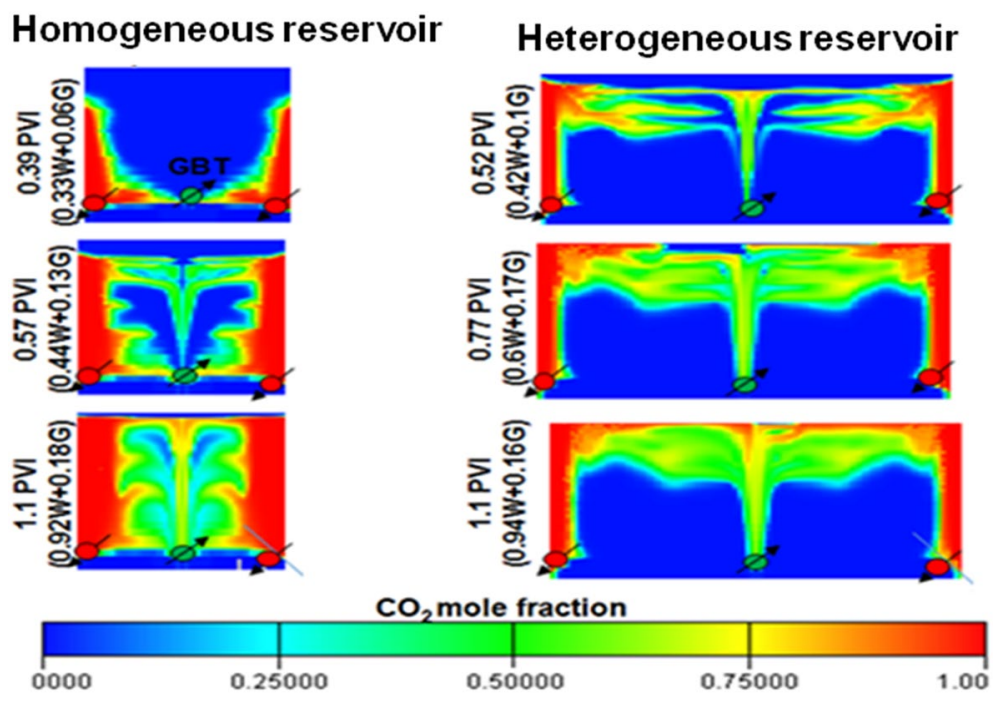

for WAG in homogeneous and heterogeneous reservoirs. The WAG shows faster gas movement in heterogeneous reservoir compared to homogeneous reservoir. Initially, the gas movement direction is different in homogeneous reservoir compared to heterogeneous reservoir as shown in the first-row snapshots of Fig. 22. The gas gravity override is higher in heterogeneous reservoir due to presence of higher matrix permeability and HKS in upper layer compared to low permeability homogeneous reservoir, which has high permeability dolomite layer in the lower layers. The second-row snapshots show the progressive gas movement, and ultimately, the third-row snapshots show higher sweep in homogeneous reservoir compared to heterogeneous reservoir with same level of HCPVI due to HKS and utilized lower injected gas.

\section{Permeability heterogeneity impact on economics in WAG displacement}

The net present value (NPV) is the important indicator of profitability for projected investment in the WAG displacement process. The reservoir heterogeneity plays a vital role in the project economy (Bhatia et al. 2014). Ettehadtavakkol et al. (2014) show that increase in WAG ratio provides better NPV, however, after further increase in WAG ratio shows a decline in NPV, while NPV will be highest at optimum WAG ratio in both carbonate and sandstone reservoirs. However,
Fig. 23 WAG incremental oil recovery and solvent recovery relationship with HCPVI after WAG starts for homogeneous and heterogeneous reservoir

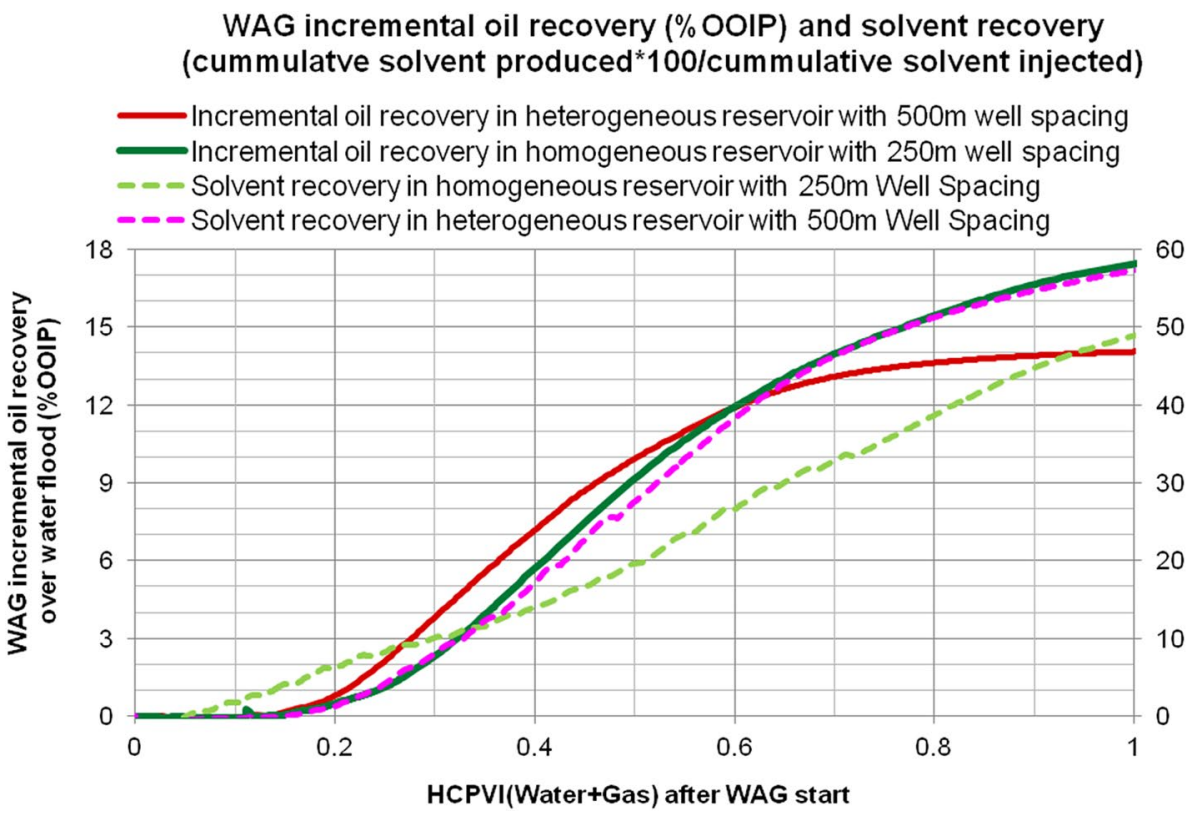


permeability heterogeneities have a significant impact on WAG ratio to achieve optimum value. The NPV is computed from the summing of all the present values from outgoing and incoming cash flows over a period (Satter and Ganesh, 1994) as presented below:

$N P V=\sum_{t=1}^{t} \frac{\left(\mathrm{C}_{\mathrm{in}}-\mathrm{C}_{\mathrm{out}}\right)_{t}}{(1+r)^{t}}-\mathrm{C}_{\mathrm{o}}$

where $\mathrm{C}_{\mathrm{in}}, \mathrm{C}_{\text {out }}, \mathrm{C}_{\mathrm{o}}, \mathrm{r}$ and $\mathrm{t}$ are the net cash inflow (Revenue) during period $t$, net cash investment during period $t$, investment costs, discount rate and number of years, respectively.

In WAG displacement, the availability of gas at field level affects greatly the economic. However, the reservoir heterogeneities also play a significant role in economics due to effect on oil recovery, solvent utilization factor, WAG response time, GOR and water production. Figure 23 shows WAG incremental oil recovery and solvent recovery relationship with HCPVI after WAG starts for homogeneous and heterogeneous reservoirs. Homogeneous reservoir shows 3\% OOIP higher recovery compared to heterogeneous reservoir at $1 \mathrm{HCPVI}$, which was expected due to less gas gravity override. However, the heterogeneous reservoir has higher amount of gas injected and higher solvent recovery, which was also expected due to high matrix permeability and higher gas gravity override through upper HKS layers. The homogeneous reservoir requires double number of wells due to tight permeability; hence, higher capital cost is required to be invested compared to heterogeneous reservoir. Simulation results show that heterogeneous reservoir shows faster response with higher initial oil acceleration production but with lower initial solvent utilization factor compared to homogeneous reservoir in miscible WAG displacement. Hence, all input advantages and disadvantage put together and the economics calculation was carried out to see final higher miscible WAG impact benefit in both the reservoirs. Table 1 shows economics evaluation of these two reservoirs and confirms that heterogeneous high permeability reservoir has better NPV compared to low permeability homogeneous reservoir. Hence, it is not always true that miscible WAG benefit (better NPV) is higher in homogeneous reservoir compared to heterogeneous reservoir, because it depends on the combined effect of incremental oil recovery, GOR production level, WAG response time, faster oil acceleration, solvent utilization factor and solvent recovery.

\section{Summary and conclusions}

The results of this study show that the permeability heterogeneities play a significant role in miscible WAG performance and their economics. The results of permeability heterogeneities impact on WAG performance are given below:

- The presence of HKS in upper layers in heterogeneous reservoir shows poor vertical sweep due to capillary holding phenomena;

- The permeability heterogeneities decrease the ultimate oil recovery (EUR), higher GOR and water cut production. However, heterogeneous reservoir shows initially faster WAG response to accelerate the oil recovery, while in later time stage, the oil recovery is reduced compared to homogeneous reservoir due to relatively piston-like uniform displacement behavior in homogeneous reservoir;

- Initially, solvent utilization factor is higher in heterogeneous reservoir, while in later stage solvent utilization factor is nearly the same for both homogeneous and heterogeneous. The total gas utilization is higher in heterogeneous reservoir compared to homogenous reservoir;

- The heterogeneous reservoir shows initially faster WAG response to incremental oil recovery, while in later time the incremental oil recovery was reduced due to relatively piston-like uniform displacement in homogeneous reservoir;

- Hysteresis (presence in $\mathrm{P}_{\mathrm{c}}, \mathrm{K}_{\mathrm{rg}}$ and $\mathrm{K}_{\mathrm{w}}$ ) has insignificant impact on WAG incremental oil recovery and GOR production in heterogeneous reservoir. In the homogeneous reservoir, hysteresis in $\mathrm{K}_{\mathrm{rg}}$ also has insignificant impact. However, without hysteresis in $\mathrm{K}_{\mathrm{rw}}$ reduces the oil recov-

Table 1 Economic indicators in homogeneous reservoir versus heterogeneous reservoir in miscible WAG displacement

\begin{tabular}{|c|c|c|c|c|c|c|c|c|c|}
\hline \multirow[t]{2}{*}{ At Year } & \multicolumn{2}{|c|}{$\begin{array}{l}\text { Incremental Cum. Oil } \\
\text { (MMstb) }\end{array}$} & \multicolumn{2}{|l|}{ CAPEX (MM\$) } & \multicolumn{2}{|l|}{ UDC (\$/bbl) } & \multicolumn{2}{|l|}{ UTC $(\$ / b b l)$} & \multirow{2}{*}{$\begin{array}{l}\text { Heterogeneous } \\
\text { reservoir NPV } \\
\text { related to homo- } \\
\text { geneous reservoir } \\
(\%)\end{array}$} \\
\hline & Homogeneous & Heterogeneous & Homogeneous & $\begin{array}{l}\text { Het- } \\
\text { eroge- } \\
\text { neous }\end{array}$ & Homogeneous & Heterogeneous & Homogeneous & $\begin{array}{l}\text { Het- } \\
\text { eroge- } \\
\text { neous }\end{array}$ & \\
\hline 30 & 5.1 & 16.2 & 62 & 35 & 12.2 & 2.2 & 25 & 11 & 125 \\
\hline 55 & 11.8 & 23 & 62 & 35 & 5.3 & 1.5 & 20 & 9 & 135 \\
\hline 100 & 15.7 & 24.5 & 62 & 35 & 3.9 & 1.4 & 18 & 8 & 135 \\
\hline
\end{tabular}


ery and GOR production, while oil recovery and GOR further reduce if there is no hysteresis in capillary pressure;

- Compositional simulation overestimates 2-3 (\% OOIP) WAG incremental recovery at 1 HCPVI in both homogeneous and heterogeneous reservoirs due to not consideration of the un-contacted oil saturation $\left(\mathrm{S}_{\mathrm{orm}}\right)$;

- The higher matrix permeability shows more gas gravity override and early gas breakthrough (GBT) with higher GOR compared to low matrix permeability due to more advancement of gravity force. The HKS in upper layers causes significant gas override and fast gas breakthrough. The presence of high permeability dolomite layer in bottom of reservoir increases water breakthrough due to gravity effect. The tighter homogeneous reservoir shows higher gas gravity overrides with wider well spacing compared to heterogeneous reservoir due to higher gravity force dominant over viscous force;

- The economic analysis shows that the miscible WAG application is not always higher beneficial (high NPV) for homogeneous reservoir compared to heterogeneous reservoir due to integrated effect of incremental oil recovery, GOR, WAG response, faster oil acceleration, solvent recovery and gas utilization.

Acknowledgements The authors gratefully acknowledge the management of Kuwait Oil Company (KOC), Kuwait ADNOC (Abu Dhabi National Oil Company), UAE, IIT (ISM), Dhanbad, for their support and permission to publish this paper.

\section{Declarations}

Conflict of interest Authors declare no competing financial interests or personal relationships with other people or organizations that could inappropriately influence (bias) our work.

Open Access This article is licensed under a Creative Commons Attribution 4.0 International License, which permits use, sharing, adaptation, distribution and reproduction in any medium or format, as long as you give appropriate credit to the original author(s) and the source, provide a link to the Creative Commons licence, and indicate if changes were made. The images or other third party material in this article are included in the article's Creative Commons licence, unless indicated otherwise in a credit line to the material. If material is not included in the article's Creative Commons licence and your intended use is not permitted by statutory regulation or exceeds the permitted use, you will need to obtain permission directly from the copyright holder. To view a copy of this licence, visit http://creativecommons.org/licenses/by/4.0/.

\section{References}

Adeoye, O. M., Gerges, N., Bin Ujal , N. N., Noordin, F. B., El Din, S. S., Ismail, A. M., ... \& Yaslam, M. M. (2015, November). Integrated evaluation approach and implications of high permeability streaks in giant carbonate oilfield. In Abu Dhabi International
Petroleum Exhibition and Conference. Society of Petroleum Engineers.

Afzali S, Rezaei N, Zendehboudi S (2018) A comprehensive review on enhanced oil recovery by water alternating gas (WAG) injection. Fuel 227:218-246

Ahdaya, M., \& Imqam, A. (2020, June). Miscible Gas Injection Application for Enhanced oil Recovery: Data Analysis. In 54th US Rock Mechanics/Geomechanics Symposium. OnePetro.

Ahmed, T. (2018). Reservoir engineering handbook. Gulf Professional Publishing.

Akbar M, Petricola M, Watfa M, Badri M, Charara M, Boyd A, Kenyon B (1995) Classic interpretation problems: evaluating carbonates. Oilfield Review 7(1):38-57

Akbar M, Vissapragada B, Alghamdi AH, Allen D, Herron M, Carnegie A, Stief D (2000) A snapshot of carbonate reservoir evaluation. Oilfield Review 12(4):20-21

Al Shateri, A. A. Q., Tamura, Y. U., Furuya, K., \& Bellah, S. (2009, January 1). Successful Application of 3-D Seismic Technology on Middle Cretaceous Carbonate Reservoir-Significant OIP Increasing. Society of Petroleum Engineers.

AlAli AM, AlHamdan MR, Cinar Y (2011) An Experimental study of compositional displacements in multi-layered porous media. Paper SPE 149083 presented at the SPE/DGS Saudi Arabia Section Technical Symposium and Exhibition, Al-Khobar, Saudi Arabia.

Al-Ameri, M. B., \& Shebl, H. T. (2011, January 1). Reservoir Rock Typing of a Giant Carbonate Field. Society of Petroleum Engineers.

Al-Bayati, D., Saeedi, A., White, C., Xie, Q., \& Myers, M. (2019, April). The Effects of Crossflow and Permeability Variation on Different Miscible CO2 injection Schemes Performance in Layered Sandstone Porous Media. In IOR 2019-20th European Symposium on Improved Oil Recovery (Vol. 2019, No. 1, pp. 1-10). European Association of Geoscientists \& Engineers.

Al-Mudhafar WJ, Rao DN, Srinivasan S (2018) Reservoir sensitivity analysis for heterogeneity and anisotropy effects quantification through the cyclic CO2-Assisted Gravity Drainage EOR processA case study from South Rumaila oil field. Fuel 221:455-468

Al-Mudhafar, W. J., \& Rao, D. (2017a, April). Lessons learned from the field-scale simulation of the gas-assisted gravity drainage GAGD process in heterogeneous sandstone oil reservoirs. In SPE Western Regional Meeting. OnePetro.

Al-Mudhafar, W. J., Rao, D. N., \& McCreery, E. B. (2017b, June). Evaluation of Immiscible CO2 Enhance Oil Recovery through the CGI, WAG, and GAGD Processes in South Rumaila Oil Field. In 79th EAGE Conference and Exhibition 2017 (Vol. 2017, No. 1, pp. 1-5). European Association of Geoscientists \& Engineers.

Al-Suwaidi MH, Williams MP, Ottinger G (2010) Application of digital core description methods in a reservoir characterisation study: a review of traditional versus potential future methods. SPE. https://doi.org/10.2118/137963-MS

Araktingi, U. G., \& Orr Jr, F. M. (1990, January). Viscous fingering, gravity segregation, and reservoir heterogeneity in miscible displacements in vertical cross sections. In SPE/DOE Enhanced Oil Recovery Symposium. Society of Petroleum Engineers.

Bachar S, Obara H, Watanabe M (2011) Modeling of a new field development plan for a giant offshore oilfield in the UAE. Soc Pet Eng. https://doi.org/10.2118/147956-MS

Bhatia, J., Srivastava, J. P., Sharma, A. Jitendra S. and Sangwai, J. S. (2014). Production performance of water alternate gas injection techniques for enhanced oil recovery: effect of WAG ratio, number of WAG cycles and the type of injection gas. Int. J. Oil, Gas and Coal Technology, Vol. 7, No. 2, pp.132-151. 
Birarda GS, Dilger CW, McIntosh I (1990) Re-evaluation of the miscible WAG flood in the Caroline Field. Alberta SPE Reservoir Engineering 5(04):453-545

Brantferger, K. M., Al-Jenaibi, H., Patel, H., Al-Harbi, A. S., Kompanik, G., \& Mubarak, M. I. (2011). A Team-Based Approach to History Matching a Long-History, Giant Carbonate Reservoir Using Sector Models and a Domain Decomposition Workflow. Society of Petroleum Engineers.

Brantferger, K. M., Kompanik, G., Al-Jenaibi, H., Dodge, S., \& Patel, H. (2012). Impact and Lessons of Using High Permeability Streaks in History Matching a Giant Offshore Middle East Carbonate Reservoir. Society of Petroleum Engineers.

Braun EM, Holland RF (1995) Relative permeability hysteresis: laboratory measurements and a conceptual model. SPE Reserv Eng 10(03):222-322

Brock, D. C., \& Orr Jr, F. M. (1991). Flow visualization of viscous fingering in heterogeneous porous media. In SPE annual technical conference and exhibition. society of petroleum engineers.

Bunge AL, Radke CJ (1982) CO2 flooding strategy in a communicating layered reservoir. J Petrol Technol 34(12):2746-2756

Bushara MN, Baslaib SM (1997) Chronofacies discontinuities: precise approach for reservoir layering-An example from carbonate reservoir, Offshore Abu Dhabi. Society of Petroleum Engineers, UAE

Bushara MN, El Tawel A, Borougha H, Dabbouk C, Qotb M (2002) Effective Permeability Modeling: Geostatistical Integration of Permeability Indicators. Society of Petroleum Engineers, OffshoreAbu Dhabi

Caudle BH, Dyes AB (1958) Improving miscible displacement by gaswater injection. Trans AIME 213(01):281-283

Chakravarthy, D., Muralidharan, V., Putra, E., Hidayati, D., \& Schechter, D. S. (2006). Mitigating oil bypassed in fractured cores during $\mathrm{CO} 2$ flooding using WAG and polymer gel injections. In SPE/DOE symposium on improved oil recovery. OnePetro.

Chang-lin, L., Xin-wei, L., Xiao-liang, Z., Ning, L., Hong-na, D., Huan, W., \& Yong-ge, L. (2013, October). Study on enhanced oil recovery technology in low permeability heterogeneous reservoir by water-alternate-gas of CO2 flooding. In SPE Asia Pacific Oil and Gas Conference and Exhibition. OnePetro.

Chen HL, Wilson SD, Monger-McClure TG (1999) Determination of relative permeability and recovery for North Sea gas-condensate reservoirs. SPE Reservoir Eval Eng 2(04):393-402

Chen S, Li H, Yang D, Tontiwachwuthikul P (2010) Optimal parametric design for water-alternating-gas (WAG) process in a $\mathrm{CO} 2$ miscible flooding reservoir. J Can Pet Technol 49(10):75-82

Christensen JR, Stenby EH, Skauge A (2001) Review of WAG field experience. SPE Reserv Eval Eng 4(02):97-106

Christensen, J. R., Larsen, M., \& Nicolaisen, H. (2000, October). Compositional simulation of water-alternating-gas processes. In SPE annual technical conference and exhibition. OnePetro.

Clancy JP, Gilchrist RE, Cheng LHK, Bywater DR (1985) Analysis of nitrogen-injection projects to develop screening guides and offshore design criteria. J Petrol Technol 37(06):1097-1104

CRAIG, F. (1971) The reservoir engineering aspects of waterflooding. Society of Petroleum Engineers of AIME, Monograph Series

Cuesta, J. F., \& Merrit, G. C. (1982). Caroline WAG (water-alternatinggas) project injectivity and interference test a field example.

Cullick AS, Lu HS, Jones LG, Cohen MF, Watson JP (1993) WAG may improve gas-condensate recovery. SPE Reserv Eng 8(03):207-213

Dawe RA, Caruana A, Grattoni CA (2011) Immiscible displacement in cross-bedded heterogeneous porous media. Transp Porous Media 87(1):335-353
Debbabi Y, Jackson MD, Hampson GJ, Fitch PJ, Salinas P (2017) Viscous crossflow in layered porous media. Transp Porous Media 117(2):281-309

DiCarlo DA, Sahni A, Blunt MJ (2000) The effect of wettability on three-phase relative permeability. Transp Porous Media 39(3):347-366

Dong M, Foraie J, Huang S, Chatzis I (2005) Analysis of water-alternate-gas (WAG) injection using micromodel tests. J Can Pet Technol 44(2):1-9

Donaldson, E. C., Chilingarian, G. V., \& Yen, T. F. (Eds.). (1989). Enhanced oil recovery, II: Processes and operations. Elsevier.

Egermann, P., Vizika, O., Dallet, L., Requin, C., \& Sonier, F. (2000, October). Hysteresis in three-phase flow: experiments, modeling and reservoir simulations. In SPE European petroleum conference. OnePetro.

Ettehadtavakkal A, Lake LW, Bryant SL (2014) $\mathrm{CO}_{2}$-EOR and storage design optimization. Int J Greenhouse Gas Control 25:79-92

Fayers FJ, Muggeridge AH (1990) Extensions to Dietz theory and behavior of gravity tongues in slightly tilted reservoirs. SPE Reserv Eng 5(04):487-494

Fenwick DH, Blunt MJ (2013) Network modeling of three-phase flow in porous media. SPE J 3(01):86-96

Figuera, L., Al-Hammadi, K., Bin-Amro, K., \& Al-Aryani, F. (2014). Performance Review and field measurements of an EOR-WAG project in tight oil carbonate reservoir-Abu Dhabi onshore field experience. In Abu Dhabi international petroleum exhibition and conference.

Gharbi, R. B., Peters, E. J., Elkamel, A., \& Afzal, N. (1997). The effect of heterogeneity on the performance of EOR processes with horizontal Wells. In SPE Western Regional Meeting. OnePetro.

Ghedan, S. G., Thiebot, B. M., \& Boyd, D. A. (2006, December 1). Modeling Original Water Saturation in the Transition Zone of a Carbonate Oil Reservoir. Society of Petroleum Engineers.

Ghedan, S. G. (2009). Global laboratory experience of CO2-EOR flooding. In SPE/EAGE reservoir characterization and simulation conference. OnePetro.

Ghomian, Y. (2008). Reservoir simulation studies for coupled carbon dioxide sequestration and enhanced oil recovery. The university of texas at Austin.

Giordano, R. M., Salter, S. J., \& Mohanty, K. K. (1985). The effects of permeability variations on flow in porous media. In SPE annual technical conference and exhibition. Society of Petroleum Engineers.

Gorell, S. B. (1990). Implications of water-alternate-gas injection, for profile control and injectivity. In SPE/DOE Enhanced Oil Recovery Symposium.

Gorell, S. B. (1990, April). Implications of water-alternate-gas injection, for profile control and injectivity. In SPE/DOE Enhanced Oil Recovery Symposium. OnePetro.

Green, D. W., \& Willhite, G. P. (1998). Enhanced Oil Recovery, Vol. 6, 18-27. Richardson, Texas: Textbook Series, SPE.

Harbert, L. W. (1983, October). Low interfacial tension relative permeability. In SPE Annual Technical Conference and Exhibition. OnePetro.

Hawes, R. I., Matthews, J. D., Hawkyard, I. R., \& Fishlock, T. P. (1986). Feasibility studies of waterflooding gas condensate reservoirs. In European petroleum conference (pp. 255-264).

He, Y., Cheng, S., Qin, J., Wang, Y., Chen, Z., \& Yu, H. (2018). Pressure-transient behavior of multisegment horizontal wells with nonuniform production: theory and case study. J Energy Resour Technol, 140(9).

Heinrich, J. J., Herzog, H. J., \& Reiner, D. M. (2003, May). Environmental assessment of geologic storage of $\mathrm{CO} 2$. In second national conference on carbon sequestration (pp. 5-8). 
Henderson GD, Danesh A, Tehrani DH, Al-Shaidi S, Peden JM (1998) Measurement and correlation of gas condensate relative permeability by the steady-state method. SPE Reserv Eval Eng 1(02): $134-140$

Hiraiwa T, Suzuki K (2007) New method of incorporating immobile and non-vaporizing residual oil saturation into compositional reservoir simulation of gasflooding. SPE Reserv Eval Eng 10(01):60-65

Hoare, G., \& Coll, C. (2018). Effect of small/medium scale reservoir heterogeneity on the effectiveness of water, gas and water alternating gas WAG injection. In SPE Europec featured at 80th EAGE Conference and Exhibition. Society of Petroleum Engineers.

Holm LW (1976) Status of CO2 and hydrocarbon miscible oil recovery methods. J Petrol Technol 28(01):76-84

Hustad, O., \& Holt, T. (1992). Gravity stable displacement of oil by hydrocarbon gas after waterflooding. SPE/DOE eighth symposium on enhanced oil recovery (pp. 1-16). Tulsa: society of petroleum engineers

Jeong, M. S., Cho, J., \& Lee, K. S. (2014, August). Optimized WAG cycle and well pattern of $\mathrm{CO} 2$ EOR projects for maximum NPV in heterogeneous reservoirs. In the twenty-fourth international ocean and polar engineering conference. International society of offshore and Polar Engineers.

Joekar-Niasar V, Doster F, Armstrong RT, Wildenschild D, Celia MA (2013) Trapping and hysteresis in two-phase flow in porous media: a pore-network study. Water Resour Res 49(7):4244-4256

Johns, R. T., \& Dindoruk, B. (2013). Gas flooding. In enhanced oil recovery field case studies (pp. 1-22). Gulf professional publishing.

Jones, L. G., Cullick, A. S., \& Cohen, M. F. (1989). WAG process promises improved recovery in cycling gas condensate reservoirs: Part 1--Prototype reservoir simulation studies. In SPE Gas technology symposium. OnePetro.

Khan MY, Mandal A (2019) Vertical transmissibility assessment from pressure transient analysis with integration of core data and its impact on water and miscible water-alternative-gas injections. Arab J Geosci 12(8):1-24

Khorsandi, S., \& Johns, R. (2018). Mechanistic modeling of gravity film drainage using relative permeability equation of state. In SPE annual technical conference and exhibition. OnePetro

Knappskog, O. A. (2012). Evaluation of WAG injection at Ekofisk (Master's thesis, University of Stavanger, Norway).

Kohda, A., Bellah, S., Shibasaki, T., Farhan, Z. A., Shibayama, A., Hamami, M. A., \& Jasmi, S. A. (2017). Characterization of high-permeability streaks associated with heterogeneous stromatoporoid reefal facies and establishment of modeling workflow in carbonate reservoir, offshore Abu Dhabi. Society of petroleum engineers.

Kulkarni MM, Rao DN (2005) Experimental investigation of miscible and immiscible water-alternating-Gas (WAG) process performance. J Petrol Sci Eng 48(1-2):1-20

Kulkarni, M. M. (2003). Immiscible and miscible gas-oil displacements in porous media.

Land CS (1968) Calculation of imbibition relative permeability for two and three phase flow from rock properties. Trans Am Inst Min Metall Pet Eng 243:149-156

Landrum BL, Crawford PB (1960) Effect of directional permeability on sweep efficiency and production capacity. J Petrol Technol 12(11):67-71

Larsen JA, Skauge A (1998) Methodology for numerical simulation with cycle-dependent relative permeabilities. SPE J 3(02):163-173

Leach MP, Yellig WF (1981) Compositional model studies-CO2 oil-displacement mechanisms. Soc Petrol Eng J 21(01):89-97
Li, D., Alharbi, M. S., Ottinger, G., El-Awawdeh, R. T., Brunhuber, P., \& Al-Jasmi, S. M. (2016, September). A new method to calculate effective permeability of a naturally fractured carbonate reservoir from seismic attributes. In SPE annual technical conference and exhibition. Society of petroleum engineers.

Li, W., Shi, Q., Dong, H., Hou, R., 2020. Optimum selection of injection-production method for carbon dioxide miscible flooding in low permeability reservoirs.Geol. China.

Lien, S. C., Lie, S. E., Fjellbirkeland, H., \& Larsen, S. V. (1998). Brage Field, lessons learned after 5 years of production. In european petroleum conference. OnePetro.

Lv P, Liu Y, Chen J, Jiang L, Wu B, Liu S, Song Y (2017) Pore-scale investigation of effects of heterogeneity on $\mathrm{CO} 2$ geological storage using stratified sand packs. Greenh Gases: Sci Technol 7:972-987

Mahmoud, T., \& Rao, D. N. (2007). Mechanisms and performance demonstration of the gas-assisted gravity-drainage process using visual models. In SPE annual technical conference and exhibition. OnePetro.

Masalmeh, S. K., Hillgartner, H., Al-Mjeni, R. A.-M., \& Jing, X. (2010). Simultaneous injection of miscible gas and polymer (SIMGAP) to improve oil recovery and sweep efficiency from Layered Carbonate Reservoirs. Paper presented at the SPE EOR Conference at Oil \& Gas West Asia.

Masalmeh, S., Al-Mesmari, A., Farzaneh, A., \& Sohrabi, M. (2021). Laboratory study to investigate cyclic hysteresis in miscible and immiscible WAG experiments in carbonate reservoir. In IOR 2021 (Vol. 2021, No. 1, pp. 1-16). European association of geoscientists \& engineers.

McGuire, P. L., Redman, R. S., Jhaveri, B. S., Yancey, K. E., \& Ning, S. X. (2005, March). Viscosity reduction WAG: an effective EOR process for North Slope viscous oils. In SPE Western regional meeting. OnePetro.

Miyamoto, H., Kohda, A., Alfarhan, Z. A., Shibasaki, T., Bellah, S., Al-Ameri, M. B., \& Jasem, S. M. (2017). Maximize the value of 3D seismic with AVO inversion for reservoir modeling and field development optimizing, offshore Abu Dhabi, UAE. Society of petroleum engineers.

Mohamed, S. S. E. D., Dernaika, M., \& Kalam, M. Z. (2011). The impact of heterogeneity and multi-scale measurements on reservoir characterization and STOOIP estimations. Paper presented at the SPE reservoir characterisation and simulation conference and exhibition.

Muskat, M. (1981). Physical principles of oil production.

Namba T, Hiraoka T (1995) Capillary force barriers in a carbonate reservoir under waterflooding. Society of Petroleum Engineers, In Middle East Oil Show. https://doi.org/10.2118/29773-MS

Nguyen, T. B., Dang, T. Q., Chen, Z., \& Nghiem, L. X. (2015, June). Effects of lithofacies and reservoir heterogeneity on improved oil recovery processes. In SPE Canada heavy oil technical conference. Onepetro.

Pan, Y., Kamal, M. M., \& Narr, W. (2018). Fieldwide determination of directional permeabilities using transient well testing. SPE reservoir evaluation \& engineering.

Panda M, Ambrose JG, Beuhler G, McGguire PL (2009) Optimized eor design for the Eileen west end area, greater Prudhoe bay. SPE Reserv Eval Eng 12(01):25-32

Pande, K. K. (1992, October). Effects of gravity and viscous crossflow on hydrocarbon miscible flood performance in heterogeneous reservoirs. In SPE annual technical conference and exhibition. OnePetro.

Perrin J-C, Benson S (2010) An Experimental study on the influence of sub-core scale heterogeneities on $\mathrm{CO} 2$ distribution in reservoir rocks. Transp Porous Media 82:93-109

Poli, E., Maza, C., Virgone, A., Gisquet, F., Fraisse, C., \& PabianGoyheneche, C. (2009, January). High permeability streaks

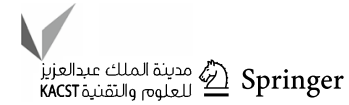


characterisations in middle East carbonate. In international petroleum technology conference. International petroleum technology conference.

Rashid B, Muggeridge AH, Bal A, Williams G (2012) Quantifying the impact of permeability heterogeneity on secondary-recovery performance. SPE J 17(02):455-468

Ren, B., Male, F., Wang, Y., Baqués, V., Duncan, I., \& Lake, L. (2019). Oil saturation in residual oil zones and its effect on $\mathrm{CO} 2 \mathrm{WAG}$ injection strategies. In SPE annual technical conference and exhibition. Society of petroleum engineers.

Rogers, J. D., \& Grigg, R. B. (2000, April). A literature analysis of the WAG injectivity abnormalities in the $\mathrm{CO} 2$ process. In SPE/DOE improved oil recovery symposium. OnePetro.

Ruelland, P. J., \& Bu-Hindi, H. (2009, January 1). High Permeability Layers in Carbonates: Innovative 3D modeling Approach in Lower Cretaceous reservoirs, offshore Abu Dhabi. International Petroleum Technology Conference.

Sanchez, N. L. (1999). Management of water alternating gas (WAG) injection projects. In Latin American and Caribbean petroleum engineering conference. Society of petroleum engineers.

Saneifar M, Heidari Z, Linroth M, Purba SA (2017) Effect of heterogeneity on fluid-injectivity loss during water-alternating-gas injection in the scurry area canyon reef operators committee unit. SPE Reserv Eval Eng 20(02):293-303

Satter, A., \& Thakur, G. C. (1994). Integrated petroleum reservoir management: a team approach. PennWell Books.

Schembre JM, Kovscek AR (2003) A technique for measuring two-phase relative permeability in porous media via X-ray $\mathrm{CT}$ measurements. J Petrol Sci Eng 39(1-2):159-174

Sedaghatinasab R, Kord S, Moghadasi J, Soleymanzadeh A (2021) Relative permeability hysteresis and capillary trapping during $\mathrm{CO} 2$ EOR and sequestration. Int J Greenh Gas Control 106:103262

Shahverdi H, Sohrabi M, Fatemi M, Jamiolahmady M (2011) Three-phase relative permeability and hysteresis effect during WAG process in mixed wet and low IFT systems. J Petrol Sci Eng 78(3-4):732-739

Shook, G. M., \& Mitchell, K. M. (2009, October). A robust measure of heterogeneity for ranking earth models: the F PHI curve and dynamic Lorenz coefficient. In SPE annual technical conference and exhibition. OnePetro.

Singhal, A. K., \& Springer, S. J. (2006). Characterization of reservoir heterogeneity based on performance of infill wells in waterfloods. J Can Pet Technol, 45(07).

Effect of wettability on the oil recovery by WAG, presented at the 7th IOR symp, Moscow.

Skauge, A., \& Larsen, J. A. (1994, September). Three-phase relative permeabilities and trapped gas measurements related to WAG processes. In SCA 9421, proceedings of the international symposium of the society of core analysts, Stavanger, Norway.

Skene, K. I., Yamamoto, K., Brantferger, K., Quintero, M., Kompanik, G., Ottinger, G., \& Manal, A. H. (2014). Accounting for multi-scale permeability systems in reservoir models of a giant offshore oil field, Abu Dhabi-Balancing matrix versus excess permeability and its impact on reservoir performance. In Abu Dhabi international petroleum exhibition and conference. OnePetro.

Sohrabi, M., Henderson, G. D., Tehrani, D. H., \& Danesh, A. (2000). Visualisation of oil recovery by water alternating gas (WAG) injection using high pressure micromodels-water-wet system. In SPE annual technical conference and exhibition.

Sorbie KS, Walker DJ (1988) A study of the mechanism of oil displacement using water and polymer in stratified laboratory core systems. Paper SPE/DOE 17397 presented at the SPE/DOE Enhanced Oil Recovery Symposium, Tulsa, OK, 17-20 April

Spiteri, E. J., \& Juanes, R. (2004). Impact of relative permeability hysteresis on the numerical simulation of WAG injection. In SPE annual technical conference and exhibition. OnePetro.
Stalkup FI Jr (1983) Status of miscible displacement. J Petrol Technol 35(04):815-826

Sultan, A. A., Sit, K. H., Alrougha, H. B., Khouri, N. A., \& Edwards, H. E. (2005). Resolution of a multi-set, strike-slip dominated fault system, identified from 3D seismic, in early Cretaceous carbonate reservoir sequences of a giant offshore field in Abu Dhabi. Society of petroleum engineers.

Summapo, S., Srisuriyachai, F., \& Athichanagorn, S. (2013, November). Evaluation of $\mathrm{CO} 2$ flooding in multi-layered heterogeneous reservoir. In Paper ID 124 presented at the 11th international conference on mining, Materials and petroleum engineering, Chiang Mai, Thailand (pp. 11-13).

Surguchev, L. M., Korbol, R., Haugen, S., \& Krakstad, O. S. (1992, January). Screening of WAG injection strategies for heterogeneous reservoirs. In European petroleum conference. Society of petroleum engineers.

Surguchev, L. M., Korbol, R., Haugen, S., \& Krakstad, O. S. (1992, November). Screening of WAG injection strategies for heterogeneous reservoirs. In European petroleum conference. OnePetro.

Tabatabaei Nezhad, S. A. R., Rahimzadeh Mojarad, M., Paitakhti Oskouei, S. J., Moghadas, J. S., \& Farahmand, D. R. (2006). Experimental study on applicability of water alternating $\mathrm{CO} 2$ injection in the secondary and tertiary recovery. In International oil conference and exhibition in Mexico. OnePetro.

Tavousi Z, Kharrat R, Hashemi A, Ghoodjani E (2016) Case study: comparison of enhanced heavy-oil recovery by CGI, WAG, and GAGD. Energy Sources, Part a: Recovery, Util, Environ Effects 38(15):2181-2189

Temizel, C., Purwar, S., Agarwal, A., Abdullayev, A., Urrutia, K., \& Chacon-Garcia, A. J. (2014). Investigation of significance of critical components in optimization of WAG Injection processes under uncertainty. In SPE energy resources conference.

Thakur GC, Satter A (1998) Integrated waterflood asset management. Tulsa, Okla, PennWell Book

Tidwell, V.,Wilson, J. (2000). "Heterogeneity, permeability patterns, and permeability upscaling: physical characterization of a block of Massillon sandstone exhibiting nested scales of heterogeneity", SPE Reserv Eval Eng 3(4), 283291.

Torabi, F., Jamaloei, B. Y., Zarivnyy, O., Paquin, B. A., Rumpel, N. J., \& Wilton, R. R. (2010). Effect of oil viscosity, permeability and injection rate on performance of waterflooding, $\mathrm{CO} 2$ flooding and WAG processes on recovery of heavy oils. In Canadian unconventional resources and international petroleum conference. Society of petroleum engineers.

Touray, S. (2013). Effect of water alternating gas injection on ultimate oil recovery. Master of Engineering Dalhousie University, 25.

Venkitadri, V. S., Shebl, H. T., Shibasaki, T., Dabbouk, C. A., \& Salman, S. M. (2005). Reservoir Rock Type Definition In A Giant Cretaceous Carbonate. Society of Petroleum Engineers.

Virnovsky GA, Helset HM (1996) Stability of displacement fronts in WAG operations. SPE J 1(04):383-394

Voleti, D. K., Al Mazrooei, S., \& Obaid Al Nuaimi, L. (2014). Water saturation modeling of complex carbonate reservoir: a case study of challenging highly impacted reservoir by diagenesis processes. In Abu Dhabi international petroleum exhibition and conference. SPE.

White CD, Willis BJ, Narayanan K, Dutton SP (2001) Identifying and estimating significant geologic parameters with experimental design. SPE J 6(03):311-324

Wu, X., Ogbe, D. O., Zhu, T., \& Khataniar, S. (2004). Critical design factors and evaluation of recovery performance of miscible displacement and WAG process. In Canadian International Petroleum Conference. Petroleum Society of Canada.

Xie J, Hu X, Liang H, Li Z, Wang R, Cai W, Nassabeh SMM (2020) Experimental investigation of permeability heterogeneity impact on the miscible alternative injection of formation Brine-Carbon dioxide. Energy Rep 6:2897-2902 
Xu ZX, Li SY, Li BF, Chen DQ, Liu ZY, Li ZM (2020) A review of development methods and EOR technologies for carbonate reservoirs. Pet Sci 17:990-1013

Yamamoto, K., Kompanik, G., Brantferger, K., Al Zinati, O., Ottinger, G., Al Ali, A., ... \& Edwards, H. E. (2012). Permeability Model Conditioning of a Thin, Heterogeneous High-K Dolomitized Unit in a Supergiant Carbonate Field, Offshore Abu Dhabi. In Abu Dhabi International Petroleum Conference and Exhibition. SPE.

Yokoyama, Y., \& Lake, L. W. (1981). The effects of capillary pressure on immiscible displacements in stratified porous media. In SPE Annual Technical Conference and Exhibition. OnePetro.

Yu, G. Y., Namani, M. N., Kleppe, J. K., \& Rossen, W. R. (2017). Gravity Override and Vertical Sweep Efficiency in Dipping Reservoirs. In IOR 2017-19th European Symposium on Improved Oil Recovery (Vol. 2017, No. 1, pp. 1-10). European Association of Geoscientists \& Engineers.
Zahoor, M. K., Derahman, M. N., \& Yunan, M. H. (2011). WAG process design-an updated review. Brazilian J Pet Gas, 5(2).

Zhang P, Brodie J, Daae V, Erbas D, Duncan E (2013) BP North sea miscible gas injection projects review. In: SPE offshore Europe oil and gas conference and exhibition. OnePetro

Zhao Y, Song Y, Liu Y, Jiang L, Zhu N (2011) Visualization of CO 2 and oil immiscible and miscible flow processes in porous media using NMR micro-imaging. Pet Sci 8(2):183-193

Publisher's Note Springer Nature remains neutral with regard to jurisdictional claims in published maps and institutional affiliations. 